\title{
ARE EXTERNAL SHOCKS RESPONSIBLE FOR THE INSTABILITY OF OUTPUT IN LOW-INCOME COUNTRIES?
}

\author{
Claudio Raddatz ${ }^{1}$
}

\begin{abstract}
External shocks, such as commodity price fluctuations, natural disasters, and the role of the international economy, are often blamed for the poor economic performance of low-income countries. This paper quantifies the impact of these different external shocks using a panel vector auto-regression approach and compares their relative contributions to output volatility in lowincome countries vis-a-vis internal factors. We find that external shocks can only explain a small fraction of the output variance of a typical low-income country. Internal factors are the main source of fluctuations. From a quantitative perspective, the output effect of external shocks is typically small in absolute terms, but significant relative to the historic performance of these countries.
\end{abstract}

\section{World Bank Policy Research Working Paper 3680, August 2005}

The Policy Research Working Paper Series disseminates the findings of work in progress to encourage the exchange of ideas about development issues. An objective of the series is to get the findings out quickly, even if the presentations are less than fully polished. The papers carry the names of the authors and should be cited accordingly. The findings, interpretations, and conclusions expressed in this paper are entirely those of the authors. They do not necessarily represent the view of the World Bank, its Executive Directors, or the countries they represent. Policy Research Working Papers are available online at http://econ.worldbank.org.

\footnotetext{
${ }^{1}$ Development Economics Research Group, World Bank; email: craddatz@worldbank.org. I am grateful to Mark Dorfman, Aart Kraay, Vikram Nehru, Angelique de Plaa, Sergio Schmukler, and Ekaterina Vostroknutova for useful comments.
} 


\section{Introduction}

Economic performance in low-income countries is highly unstable. During 1965 to 1997, the standard deviation of output growth and the frequency of drops in real GDP larger than 3 percent were respectively two and five times larger in low-income countries than in high-income countries. This larger volatility and prevalence of negative shocks can become especially burdensome for lowincome countries because of their low average growth rates and high fraction of population living under poverty.

Among policymakers, external shocks, such as terms-of-trade fluctuations, international conditions, natural disasters, or aid volatility, are often explicitly or implicitly blamed for this volatile performance. Recent reports by the IMF, World Bank, and UNCTAD state that "exogenous shocks ... can have a significant negative impact on developing countries' growth, macroeconomic stability, debt sustainability and poverty", "low-income countries are particularly vulnerable to natural disasters, terms-of-trade shocks, and other adverse shocks", and that "the level and volatility of world commodity prices are an important influence on economic growth and the incidence of poverty in $L D C s " .^{2}$

The focus on external shocks is understandable given some structural characteristics of lowincome countries, particularly the importance of primary commodities on their exports, their higher exposure to natural disasters, and their dependence on aid flows. ${ }^{3}$ However, this simple list of structural features does not prove that external shocks are important, either in absolute or relative terms. Internal shocks resulting from conflicts, political instability, and economic mismanagement are a potentially important source of economic volatility, as suggested by the findings of Acemoglu et al. (2003) and Ahmed (2003). Also, the emphasis on external shocks seems to portray low-income countries as simple bystanders whose economic ailments are the result of factors beyond the reach of their policymakers, and gives a somewhat gloomy perspective of the prospects of these countries to achieve a sustainable and stable economic performance without experiencing major changes in

\footnotetext{
${ }^{2}$ See IMF (2003), World Bank (2004) and Unctad (2002) respepctively.

${ }^{3}$ Primary commodities, whose prices are significantly more volatile than those of industrial goods, represent about 85 percent of low-income countries' exports, foreign aid represents about 11 percent of GDI for the average LIC, and, according to a widely cited report by the World Bank (World Bank (2000)), between 1990-1998 94 percent of the world's major disasters occurred in developing countries. This emphasis has also received some support from the academic literature. For example, Easterly et al. (1993) state that: "shocks, especially those to terms of trade, play a large role in explaining the variance of GDP".
} 
their productive structures. The issue therefore speaks to the quantitative effect of external shocks and their relative importance vis-à-vis internal shocks.

This paper quantifies the impact of a comprehensive set of external shocks on the output and income of low-income countries, and compares their relative ability to explain the large cyclical fluctuations observed in these countries vis-à-vis internal factors. The external shocks considered include terms-of-trade shocks, natural disasters, changes in the condition of the international economy and international interest rates, and fluctuations in aid flows. By explicitly analyzing the impact of each of these shocks, this paper not only addresses the question of the extent to which the volatility of output in low-income countries can be attributed to external factors, but also which of these factors are relatively more important.

The effect and relative importance of these different shocks are determined using a vector autoregression (VAR) model in which external shocks are assumed to be exogenous to country-level variables. This approach explicitly considers the dynamics of the different variables, and therefore allows us to estimate their impact at various frequencies. It also permit us to separate the fraction of the variance of output that can be attributed to these external shocks from that portion that is orthogonal to them and that we associate with internal factors because the broad set of exogenous contingencies we consider covers most of the potential causes of external shocks for low-income countries.

Because of the short time dimension of the series available, we use a panel VAR model in which the dynamics of the countries in our sample are assumed identical (up to a country specific trend and constant) to increase the degrees of freedom of our estimation. The parameters of this model are estimated on a sample of 40 countries classified as low-income by the World Bank, over the period 1965-1997. A similar approach has previously been used by Deaton and Miller (1996) to estimate the impact of commodity prices in African countries, Broda (2004) to estimate the impact of terms-of-trade socks in countries with different exchange regimes, and Ahmed (2003) to determine the effect of different sources of economic fluctuations in six Latin American countries.

The results of the paper show that, on the one hand, external shocks have an economically meaningful impact on low-income countries' per-capita GDP, especially when compared with their typical performance. A one standard deviation positive shock to either per-capita GDP of highincome countries, commodity prices (our main measure of terms-of-trade), or per-capita aid flows 
results in an approximately $1 \%$ significant increase in the per-capita GDP of low-income countries. Climatic disasters (which include floods, droughts, extreme temperatures, and wind storms) and humanitarian disasters (which include famines and epidemics) result in declines in real per-capita GDP of $2 \%$ and $4 \%$, respectively. Real interest shocks and Geological disasters do not have a significant impact on real activity. The impact of these external shocks on Gross Domestic Income (GDI) is similar to their impact on GDP, with the exception of commodity price shocks, whose effect on per-capita GDI doubles their effect on per-capita GDP. Although these magnitudes may look modest in absolute value, they are significantly larger than the mean and median growth rates of low-income countries during the last decade ( $0.2 \%$ and $0.4 \%$, respectively).

On the other hand however, the results show that external shocks can account only for a small fraction of the overall variance of real GDP in low-income countries. Even in the long run, they cannot explain more than 11 percent of this variance. The remaining 89 percent is accounted for by factors that are not within the broad set of exogenous shocks we consider, and which we associate with endogenous shocks. Among the external shocks, changes in commodity price are the most important exogenous source of fluctuations (explaining 37\% of the 11 percent explained by all external shocks), followed by aid shocks (25\%), climatic disasters (14\%), humanitarian crises (12\%), and fluctuations in the GDP of high-income countries and the international interest rate (10\% and $3 \%$, respectively). We perform an extensive robustness analysis and demonstrate that these findings are very robust to changes in the details of the specification, identification assumptions, or sample period.

It is important to mention that although we find that endogenous shocks are the most important source of fluctuations, we do not make an attempt to disentangle the different sources of these shocks and their relative importance. The reason is that doing so would require us to make identification assumptions about the contemporaneous causal order among the potentially important internal variables, such as output, prices, government expenditure, and the monetary stance or the long-run effect of shocks to some of these variables. We believe that this would be a dubious exercise given the fact that, even for the case of the U.S., most empirical papers do not attempt a full decomposition of the impact of these different shocks and make only enough assumptions to identify the effect of some limited set of innovations such as monetary policy or productivity shocks.

We also take advantage of our methodology to explore a series of additional questions regarding 
the impact of external shocks. Motivated by the policy debate about external shocks and debt sustainability (see World Bank, 2003), we first look at the effect of external shocks on government expenditure and the current account. We find that, in response to shocks, government expenditure tends to move in tandem with total GDP. A negative shock thus reduces both real activity and government expenditure. Interestingly, we find that in the case of natural disasters the decline of government expenditure is proportionally smaller than the decline in output. This suggests that governments try at least partially to compensate for the negative impact of these events. With respect to the current account, the evidence suggests that it moves procyclically in response to external shocks. Low-income countries tend to borrow when facing favorable external conditions and increase their foreign asset position during bad times. This behavior is similar to the procyclicality of the current account documented for emerging markets (see Aguiar and Gopinath, 2004), and goes against the conventional wisdom that poor countries get more indebted when facing adverse external shocks.

The second issue we explore is the response of aid flows to the different external shocks, which allow us to document, at least partially, the determinants of aid, and the relative importance of supply and demand factors. We find that aid flows increase significantly as a result of an increase in the GDP of high-income countries, but decline as a result of increases on the commodity prices faced by low-income countries and their output level. Interestingly, we do not find a significant effect of natural disasters on aid flows. Finally, we look at the impact of external shocks on different groups of low-income countries, separated by their degree of openness to trade, indebtedness, and institutional quality. We document a larger impact of commodity price and interest rate shocks on the output of low-income countries that are open to trade, which is consistent with the idea that these countries are more exposed to international variables. However, we also show that the impact of shocks, especially of commodity price shocks, is much shorter lived in open countries than in closed ones. It seems therefore that the higher exposure is compensated with a quicker adjustment to these types of shocks. We also find some support for the idea that highly indebted poor countries (HIPC) are more vulnerable to external shocks. The response of these countries to the world business cycle, commodity prices, and interest rate shocks is larger and more persistent than for the rest of low-income countries. Regarding the role of institutions, we document that better institutions seem to attenuate the impact of shocks to the world business cycle and commodity 
prices, but, contrary to the findings of Burnside and Dollar (2000), we do not find in this sample a relationship between institutional quality and the impact of aid shocks.

This paper contributes to several strands of literature that have explored the link between various external shocks and real activity in developing countries. The first one focuses on the role of terms-of-trade shocks. Using growth regressions, recent papers by Collier and Gunning (1999), Dehn (2001), and Collier and Dehn (2002) have documented an important effect of commodity price shocks on growth (measured as a dummy variable that takes the value one if a shock occurs during the period over which growth rates are computed and zero otherwise). Mendoza (1995), and Kose and Riezman (1999) use instead calibrated general-equilibrium small-open-economy models and find that, compared with interest rates and productivity shocks, terms-of-trade shocks can explain a large fraction (around 50 percent) of output fluctuations in low-income countries. More closely related to the approach followed in this paper, Deaton and Miller (1996), and Hoffmaister et al. (1998) have used vector autoregressions (non-structural and structural, respectively) to estimate the impact of terms-of-trade shocks on different macroeconomic variables. ${ }^{4}$ They both find that terms-of-trade shocks account only for a small fraction of output volatility. On a similar line, Broda (2004) also uses a panel VAR approach and shows that terms-of-trade shocks have a larger impact on real output in countries with fixed exchange rates. The role of the international business cycle has been recently explored in a paper by Ahmed (2003), which looks at the relative contribution of the performance of trading partners, international interest rates, and terms-of-trade shocks on the variability of output in six emerging Latin American countries and finds that these shocks account for a small fraction of output volatility. A separate literature has looked at the economic impact of natural disasters. Most of this literature is based on case studies and not on systematic econometric evidence (see for example Albala-Bertrand, 1993; and Otero and Martí, 1994). An exception is a recent paper by Skidmore and Toya (2002), which use cross-country regressions to determine the relation between the incidence of disasters (measured as the total number of disasters per land area) and growth, and finds a positive effect of climatic disasters and a negative effect (although not always significant) of geological disasters.

This paper adds to this literature in several dimensions. First, by considering the impact of a broad set of exogenous shocks in low-income countries in a unified framework, this paper provides

\footnotetext{
${ }^{4}$ Hoffmaister et al. (1998) also includes international interest rates.
} 
a comprehensive picture of the overall contribution of external shocks to the unstable economic performance of low-income countries, and of the relative importance of each type of shock. As described above, the existing papers that focus on low-income countries had been concerned only with the impact of terms-of-trade and interest rate shocks. Second, to the best of our knowledge, this is the first paper to document the dynamic response of real activity to natural disasters and aid shocks in a systematic way. Given the importance typically attributed to these shocks in lowincome countries, this is itself an important contribution. Third, this paper provides new evidence on the determinants of aid flows to low-income countries, the impact of different external shocks on government expenditure and debt, and the role of some structural characteristics on the impact of shocks.

The rest of the paper is structured as follows. Section 2 discusses the main stylized facts about the incidence of external shocks in low-income countries and describes the measures and samples that will be used in the analysis. Section 3 explains the methodological approach and discusses its main assumptions. Section 4 presents the results of the empirical analysis. Section 5 reports on the robustness of the analysis, and Section 6 discusses extensions. Section 7 concludes.

\section{Stylized facts on external shocks in low-income countries}

It is frequently claimed that the incidence of commodity price shocks and natural disasters is higher in low-income countries than in high or middle-income countries (IMF, 2003). Their dependence in foreign aid and foreign markets, and their typically high levels of indebtedness are also frequently mentioned to argue that these countries are highly vulnerable to fluctuations in international conditions. In this section we review some of the main stylized facts regarding the incidence of external shocks in low-income countries and describe along the way the specific variables that will be used in the rest of the paper to capture these shocks.

The sample of countries to which we refer as low-income countries is shown in Table 1. The sample includes 40 countries classified as low-income by the World Bank for which there is sufficient coverage of all relevant measures of external shocks described below. The region with highest presence in the sample is Sub-Saharan Africa with 32 countries, followed by South Asia with 4, Latin America and the Caribbean with 3, and East Asia and Pacific with 1. 
The main variables used in the paper are the following. Real GDP per-capita corresponds to the PPP adjusted measure and was obtained from the Penn World Tables (version 6.1). Commodity price fluctuations are captured with the Deaton-Miller commodity-based terms-of-trade index (henceforth DM index; see Deaton and Miller (1996)). The updated data for this index was obtained from Dehn (2001). The broad terms-of-trade index corresponds to the ratio of export to import prices computed using the current and constant price values of exports and imports from the national accounts component of the Penn World Tables (version 6.1). Among these two measures of terms-of-trade, in the analysis we will focus on the DM index for two reasons. First, as correctly pointed out by Aghion et al. (2005) broad terms-of-trade indexes capture fluctuations in the exchange rate that are less arguably exogenous to the business cycles than fluctuations in commodity prices. Second, from an empirical perspective, by using the DM index we give a better chance to exogenous shocks to actually play a role because, as it will be shown later, this index has a larger explanatory power for output fluctuations than the broader terms-of-trade index. Real per capita aid flows include the flows of official development assistance (ODA) and official aid in constant 1995 US dollars, and was obtained from the WDI. Aid as a fraction of Gross National Income was also obtained from the WDI.

The variables capturing the incidence of natural disasters are non-standard and deserve further discussion. Data for natural disasters was obtained from the Emergency Disasters Database (EMDAT) maintained by the Center for Research on the Epidemiology of Disasters (CRED). This is a comprehensive database that includes data on the occurrence and effects of over 12,800 massdisasters in the world since 1900, compiled from a diversity of sources. As a general principle, to enter into the database an event has to meet any of the following conditions: there are 10 or more people reported killed; there are 100 or more people reported affected; a state of emergency is declared; or there is a call for international assistance. Similarly to Skidmore and Toya (2002), we classify disasters into three categories to increase the parsimony of the analysis. Geological disasters include earthquakes, land slides, volcano eruptions, and tidal waves. An important characteristic of this type of events is their unpredictability and relatively fast onset. The second category is Climatic disasters. This category includes floods, droughts, extreme temperatures, and wind storms (e.g. hurricanes). Compared to the previous category, some of these disasters can be forecasted well in advance (so precautions can be undertaken) and have a relatively long onset. The final category is 
what we label "Human disasters", and includes famines and epidemics. The main difference with the previous two categories is that these types of disasters affect mainly human capital instead of physical capital. For each category, we measure the incidence of disasters by counting the number of events in a given year that classify as large disasters according to the following criteria established by the International Monetary Fund (see IMF, 2003): the event affects at least half a percent of a country's population, or causes damages of at least half a percent of national GDP, or results in more than one fatality in every 10,000 people.

The different columns of Table 1 show some summary statistics for each of these variables across the sample countries (Panel A) and across income groups (Panel B). The table also shows the sample period for which there is data available for each country, and the number of countries included for each income group.

The comparison across income groups shown in Panel B reveals that, as it has been extensively documented, low-income countries have grown slower and in a more unstable way than other income groups. It also shows that commodity prices have declined on average for low-income countries. Terms of trade have also declined on average, but the decline is not particular to low-income countries. The volatility of commodity prices and terms of trade is however larger in low-income countries than in other income groups. Given the relative importance of primary commodities for low-income countries, the decline in commodity prices and their larger volatility may be especially relevant: trade represents about 53 percent of low-income countries' GDP, and commodities compose about 85 percent of their exports (compared with about 40 percent for highincome countries), while the composition of their imports is not significantly different from other income groups. We also observe in the table that aid represents a much larger fraction of GNI in low-income countries than in the rest of the world (see Column 8), which is not surprising because of the limited access of LIC to private financial markets. Also, although Column 10 shows that aid growth has been relatively stable among low-income countries, which is probably due to the fact that the income classification is based on recent data and there has been limited mobility among low-income countries in the world income distribution (see Jones, 1997), the same column makes apparent the high absolute volatility of aid flows. In fact, the standard deviation of the growth of real aid flows is one order of magnitude larger than its mean. Given the importance of aid flows for low-income countries documented in Column 8, this instability may be potentially harmful. 
Columns 11 to 13 in Table 1 show that, except for Geological disasters (which tend to be more concentrated in middle income countries), natural disasters are indeed significantly more frequent in low-income countries. Although this larger incidence may result from selection bias -an event may be more likely to be classified as a large disaster if it occurs in a low-income country, which is clearly a possibility given the criteria used by CRED and the IMF to classify disasters, this problem is unlikely to affect our results for two reasons. First, our sample is composed exclusively of lowincome countries, and selection bias among low-income countries is less likely to be a significant concern. Second, and most importantly, in our specification we will control for the average income level of a country, and the identification will be provided mainly by the time variation of the data. Selection bias will therefore be only a problem if the probability of registering an event in the database is larger in a year with relatively low income with respect to each country's average. This is clearly much less likely than having a relationship between a country's average income and the probability of registering a disaster.

In addition to commodity price fluctuations, natural disasters, or aid flows, low-income countries, like any small-open-economy, can be significantly affected by fluctuations on international demand or credit market conditions. As mentioned above, exports of low-income countries tend to be heavily concentrated on primary commodities, whose total demand is largely determined by high-income countries. Also, low-income countries tend to be heavily indebted and dependent on foreign capital, so they are potentially vulnerable to changes in international credit conditions. ${ }^{5}$ The variables we use to capture these potential sources of external shocks are the real GDP of high-income countries, and the real international interest rate measured as the six-month LIBOR in US dollars minus the change in the U.S. Producers' Price Index (PPI). ${ }^{6}$

\footnotetext{
${ }^{5}$ Changes in international interest rates may affect significantly the borrowing conditions faced by low-income countries for two reasons. First, although the actual interest rates that low-income countries can obtain in private international credit markets will of course be higher than the observed international market rates (e.g. LIBOR), the evolution of these rates would be correlated as long as the country premium paid by LICs is not very cyclical. Second, even if LIC obtain most of their financing from international financial institutions, for a given amount of concessionality the rate obtained by these countries should move one to one with the rate at which IFIs can finance their portfolio. So, as long as the concessionality is not highly cyclical, the evolution of international interest rates should be associated with the actual cost of borrowing

${ }^{6}$ It is not obvious ex-ante whether we should use a real or nominal interest rate. The choice of the real interest rate was largely motivated by its widespread use in the existing literature (see Kose and Riezman, 2001; and Ahmed, 2003, among others). The main inconvenience is that the real interest rate tends to be much more procyclical than the nominal interest rate. So, it is difficult to disentangle its effect from the effect of the world business cycle. We checked all the results using the nominal interest rate also and the conclusions of the paper are not affected, but the role of the international business cycle (interest rate) is larger (smaller) in this case.
} 
The two panels of Figure 1, which plot the evolution of the growth rates of the GDP of highincome countries, and the average DM index, terms-of-trade index, and real interest rate for lowincome countries, highlight the importance of considering the impact of shocks to aggregate demand at the global level on low-income countries. Clearly, by omitting these factors one could wrongly attribute the impact of aggregate demand fluctuations to commodity price shocks. This conclusion would not be wrong from a reduced form viewpoint, but would be misleading in the sense that commodity price fluctuations would be a proximate but not ultimate determinant of the variation of output in LIC.

\section{Estimating the impact of shocks in low-income countries}

The impact of different shocks on various aspects of a country's economic performance will be estimated using a panel vector auto-regression (panel VAR). For a given country, our structural model corresponds to:

$$
A_{0} x_{i, t}=\alpha_{i}+\beta_{i} t+\sum_{j=1}^{q} A_{j} x_{i, t-j}+\varepsilon_{i t}
$$

where $x_{i, t}=\left(z_{i, t}^{\prime}, y_{i, t}^{\prime}\right)^{\prime}, z_{i, t}^{\prime}=\left(G D P H_{t}, D M T T_{i, t}, R_{t}, G E O_{i, t}, C L I M_{i, t}, H U M_{i, t}\right)$ is a vector of exogenous variables including the (log) GDP of high-income countries $(G D P H)$, the (log) real DM commodity based terms-of-trade index $(D M T T)$, the international interest rate $(R)$, and three indicator variables capturing the occurrence of geological, climatic, or human disasters (GEO, CLIM, and HUM respectively), as described in the previous section; $y_{i, t}^{\prime}$ is a vector of "endogenous" variables, which in our benchmark specification will correspond to $y_{i, t}^{\prime}=\left(A I D_{i, t}, G D P_{i, t}\right)$, where $G D P$ is the (log) real GDP per capita (PPP adjusted) and AID is the (log) aid per capita. However, the composition of the this vector will vary across specifications, as we will replace GDP for the (log) Gross Domestic Income per capita (GDI), include the different components of GDP (Consumption, Investment, etc.), or remove $A I D$. In the notation that follows, $G D P$ represents any of these possibilities.

The main identification assumption of this paper is that the variables in $z$ do not respond to the $y$ variables at any lags. This assumption is equivalent to imposing the following block diagonal 
structure in all the $A$ matrices:

$$
A_{j}=\left[\begin{array}{cc}
A_{11}^{j} & 0 \\
A_{21}^{j} & A_{22}^{j}
\end{array}\right]
$$

where the size of the sub-matrices conforms with the dimensions of $z$ and $y$. In terms of the actual variables included within each group, this assumption implies that the terms of trade faced by a low-income country, the GDP of rich countries, the incidence of natural disasters, and the international interest rate are not affected by the present or past economic performance of any particular low-income country, but all this variables probably have a contemporaneous and lagged effect on this performance. Aid is included in the vector $y$ because although foreign aid is not determined by any particular LIC, the amount of aid flowing to a country likely responds to its economic performance. Notice that by including aid among the $y$ we are also assuming that the amount of aid flowing to a particular country does not affect its terms of trade, the occurrence of natural disasters or the conditions of the international economy, but all these variables do affect the amount of aid a country is receiving.

Given that the prices of the commodities that constitute the main export products of LIC are set in international markets, and that the economic performance of rich countries or the state of the global financial markets are unlikely to be affected by the events occurring in any particular poor country we believe these identification assumptions should not be controversial. Regarding the occurrence of natural disasters, it might be argued that, given the manner in which these events are recorded, the observation of a disaster could be correlated with a country's income. However, as explained in the previous section, the identification of the parameters comes only from the time dimension of the data, so the potential relation between a country's average income level and the probability of registering a disaster is immaterial for our identification strategy.

Although the block-diagonality assumption permits us to identify the effect of the vector of $z$ variables on each $y$ variable, identifying the impact of each $z$ variable or the output effect of aid shocks (which are part of the $y$ vector) requires further assumptions. We first assume that the occurrence of natural disasters is fully exogenous. That is, it is unrelated not only to the $y$ variables, but also to the rest of the $z$ variables. For the rest of the $z$ variables, we will follow the standard practice of imposing a lower-triangular structure on the matrix of their contemporaneous relations. In our benchmark case we assume that the contemporaneous causal order runs from 
the GDP of rich countries to the terms of trade faced by LIC and to the international interest rate. This ordering permits the international interest rate to react contemporaneously to the state of the global economy, but imposes that the feedback from the international interest rate to global output operates only with a lag. As pointed out by Ahmed (2003), this assumption is standard in studies of U.S. monetary policy that use quarterly or monthly data, but may be overly strong when using annual data as in our case. Placing terms-of-trade below the GDP of rich countries assumes that changes in the demand for commodities resulting from changes in the state of the international economy translate into changes in the relative price of these products contemporaneously, but changes in commodity prices affect rich countries' output only with a lag. This assumption is also common in VAR studies of U.S. monetary policy that control for the price puzzle by including indexes of commodity prices (see, for example, Christiano et al., 1998, and references therein). The ordering of the terms-of-trade index and the international interest rate also follows the typical ordering of commodity price indexes and interest rates in these studies. Nevertheless, in the robustness section we will also determine the impact on the results of assuming several alternative orderings among these variables. For the case of aid, we also impose a block triangular structure in the matrix of contemporaneous relations between the $y$ variables, $A_{22}^{0}$, which assumes that output responds contemporaneously to changes in aid, but aid flows to a country respond to changes in its economic conditions only after a year. Given the usual delays in the process of aid allocation (see Odedokun, 2003), we believe that this is a sensible assumption.

The identification assumptions described above translate into the following structure for the matrices of structural coefficients:

$$
A_{11}^{j}=\left[\begin{array}{cc}
a_{11}^{j} & 0 \\
3 \times 3 & 3 \times 3 \\
0 & 0 \\
3 \times 3 & 3 \times 3
\end{array}\right] \quad \forall j=0 \ldots q ; \quad a_{11}^{0}=\left[\begin{array}{ccc}
a_{11} & 0 & 0 \\
a_{21} & a_{22} & 0 \\
a_{31} & a_{32} & a_{33}
\end{array}\right] ; \quad A_{22}^{0}=\left[\begin{array}{cc}
\tilde{a}_{11} & 0 \\
m \times m & \\
\tilde{a}_{21} & \tilde{a}_{22} \\
1 \times m & 1 \times 1
\end{array}\right]
$$

where $m$ is the number of variables included in $y$ excluding $A I D$, and the size of the different sub-matrices conform with the dimension of the vectors that they multiply, as indicated by the dimensions in subscript.

Several aspects of the model deserve further discussion. The vector $y_{i t}$ is assumed to be trend stationary. There is a longstanding debate in macroeconomics about whether macroeconomic 
variables are best represented as trend or first-difference stationary (see, for example, Nelson and Plosser, 1982). Although in theory the hypothesis that the series is difference stationary can be tested, it is widely recognized that those tests have very low power, particularly in small samples (Enders, 2003). Also, although the long run properties of the alternative representations are very different, from a practical standpoint the short run forecasts obtained from them tend to be similar. In our particular case, using the Levin et al. (2002) test for unit roots in panel data, we reject the null hypothesis of a unit root for all the panel variables, GDP, DMTT, and AID, but standard Dickey-Fuller tests cannot reject the hypothesis for the variables capturing the state of the world business cycle (GDPH and $R$ ), which are common to all countries (the results of the unit root test are reported in Table A1 in the appendix). However, for these common variables we cannot take advantage of the cross-section dimension to increase the power of the tests, so we have only 31 observations. Given the low power of these test, and the small number of observations we prefer to follow the results obtained for the panel variables and estimate the system assuming that the series are trend stationary. Nevertheless, we will also estimate the model in first differences and the results, reported in the robustness section of the paper, will prove qualitatively similar. ${ }^{7}$

The model corresponds to a panel VAR in which it is assumed that the dynamics, represented by the $A$ matrices, are common across cross-sectional units. This is a standard assumption in this literature (see Broda, 2001, 2004; Ahmed, 2003; Uribe and Yue, 2003) because, given the length of the time series dimension of the data (around 30 annual observations), it is not possible to estimate country specific dynamics unless we reduce importantly the number of exogenous shocks under consideration, the number of lags, or both. However, as noticed by Pesaran and Smith (1995), this assumption may lead to obtaining coefficients that underestimate (overestimate) the short (long) run impact of exogenous variables if the dynamics differ importantly across countries. There are several reasons that lead us to believe that this concern is unlikely to be important for our results. First, we focus on a subset of relatively homogeneous countries, so the heterogeneity of the parameters is likely to be much smaller than in studies that include countries from different income groups. Second, as Pesaran and Smith (1995) also notice, the asymptotic bias tends to zero if the autoregressive coefficient in the dependent variable (in this case $G D P$ ) is close to one, which

\footnotetext{
${ }^{7}$ Broda $(2001,2004)$ uses a similar approach to determine the effect of terms-of-trade fluctuations in countries with different exchange regimes. The main difference between his approach and ours is that he assumes the variables are difference stationary and analyzes the VAR for the changes in the logs.
} 
will be the case in our model. Third, as demonstrated by Pakes and Griliches (1984), if differences in slope coefficients are uncorrelated with the exogenous variables the estimated parameters would be consistent estimators of the average coefficients. This is an important result, as we do not see a particular reason to believe that the effect of say terms of trade in a country should be determined by the level of terms of trade. Most likely, it will depend on idiosyncratic country characteristics. Finally, this concern suggests that, if anything, we would be overestimating the long run effect of the exogenous shocks, so their real role into explaining the unconditional variance of output would be even smaller than suggested by our results.

Regarding the number of lags, standard lag selection tests place it between one and five depending on the criteria used to punish the loss of degrees of freedom. We use an intermediate value of 3 lags in our benchmark specification, which corresponds to the number of lags used by Deaton and Miller (1996). As a robustness check, we also estimate the parameters of the model with one and five lags, and, as it will be shown, the results would be largely unaffected.

Under the identification assumptions described above, the parameters of the model can be estimated using a two-step procedure in which we first estimate by Seemingly Unrelated Regressions (SUR) the parameters of each of the following systems of reduced form equations:

$$
\begin{aligned}
& z_{i, t}^{1}=\tilde{a}_{i}+\tilde{b}_{i} t+\sum_{j=1}^{q_{1}} \tilde{B}_{j} z_{i, t-j}^{1}+u_{i, t}^{z} \\
& y_{i, t}=a_{i}+b_{i} t+\sum_{j=0}^{q_{2}} B_{j}^{z} z_{i, t-j}+\sum_{j=1}^{q_{2}} B_{j}^{y} y_{i, t-j}+u_{i, t}^{y}
\end{aligned}
$$

where $z_{i, t}^{1}=\left(G D P H_{t}, D M T T_{i, t}, R_{t}\right)$. We then recover the impulse-response functions (IRF) to each of the structural shocks (the $\epsilon$ in Eq. (1)) using these reduced form coefficients and the Cholesky decompositions of the corresponding variance-covariance matrices of errors. Notice that given the assumption of full exogeneity, the variables capturing the occurrence of natural disasters do not have a corresponding equation in the reduced form system. So, to estimate their contribution in the variance decomposition we will use their empirical variance. This is equivalent to assuming that the occurrence of a disaster is a random variable that follows a Bernoulli distribution with the same probability across countries. We will relax this assumption by looking at the results in different sub-samples of countries with arguably different ex-ante probabilities of being affected by each type of disaster. The confidence bands for the IRF will be estimated by parametric 
bootstrapping assuming normally distributed reduced form errors. ${ }^{8}$

\section{Results}

\subsection{The impact of external shocks on real activity}

The dynamic response of output to the different external shocks is depicted in Figure 2. The different panels of this figure show the impulse-response functions (IRF) of (log) real GDP (GDP) to the occurrence of Geological, Climatic, and Human disasters, and to one-standard-deviation orthogonal shocks to the output of high-income countries $(G D P H)$, the DM index $(D M T T)$, the international interest rate $(R)$, and real per-capita aid $(A I D)$ under the benchmark identification assumptions. As the model was estimated in logs, the IRF show the log deviations of real GDP with respect to its baseline level, which contains a linear trend, so they can be interpreted as percentage changes. The continuous line depicts the point estimate of the IRF, and the broken lines show the 90 percent confidence bands obtained from the empirical distribution as described above.

The first panel of Figure 2 shows that a one standard deviation shock to the output of highincome countries (which corresponds to a 1 percent increase of $G D P H$ with respect to its baseline level) results in an almost immediate and statistically significant increase of 0.7 percent in GDP. Notice that the response of $G D P$ to $G D P H$ is almost one to one, which indicates that output in LIC is highly sensitive to fluctuations in the world business cycle. A similar but more protracted impact is observed after a shock to commodity prices (Panel B). In this case the shock corresponds to a 14 percent increase in commodity prices with respect to their baseline level and results in a significant 0.9 percent increase in GDP after about four years. The impact of a shock to the international real interest rate $R$ (Panel $\mathrm{C}$ ) is not statistically significant at any frequency, and although the point estimate suggests a positive effect during the first three years, the underlying magnitude is small (0.4 percent at the peak). This positive effect is not surprising given the positive

\footnotetext{
${ }^{8}$ The procedure can be briefly described as flollows: (i) we use the estimated variance-covariance matrix of the reduced form errors to simulate a random realization of the perturbations; (ii) we use the initial values of the different variables, the baseline coefficients, and the simulated perturbations to simulate a new set of observations for the variables in the VAR; (iii) we use these simulated observations to estimate a new set of coefficients; (iv) we repeat this exercise 200 times (the procedure is much slower than standard montecarlo over the parameters but requires less assumptions); (v) we compute the IRF for each set of coefficients obtained from the bootstrapping; (vi) we build a 90 percent confidence interval for the IRF by taking the envelope of the 90 percent of the IRF that are closer to the baseline IRF according to the euclidean norm.
} 
correlation between the real interest rate and the world business cycle.

Panels D to F show the dynamic response of output to each of the three classes of natural disasters under consideration, Geological, Climatic, and Human. In these cases, the shock corresponds to the variable indicating the occurrence of each of these disasters taking the value of 1 in year zero. By definition these events are not serially correlated, also, the identification assumptions imply that they do not affect the commodity price index or the international variables, so the persistence of the dynamic response is only due to the autocorrelation of output and aid. The figures show that Geological disasters have a small and non-significant impact on output. The lack of significance is not surprising given that only eight countries in our sample experienced a geological disaster during the sample period (see Table 1). On the contrary, the impact of Climatic and Human disasters is large and statistically significant. A Climatic disaster results in a 2 percent decline in real output one year after the event. In the case of a Human disaster, the decline is of 4 percent. Notice also that the effect of a Human disaster is more persistent. According to the point estimates, the impact of a climatic disaster has disappeared after 5 years, while the effect of a Human disaster dies out only after year 10 .

Panel G shows the impact of a shock to real per-capita aid on real per-capita GDP. We observe that unexpected increases in aid have a clear positive impact on real output. A one-standarddeviation shock to aid (which corresponds to a 30 percent increase) results in a significant 1 percent increase in real GDP after three years. The final panel of Figure 2 presents the dynamic response of $G D P$ to its own innovation.

The dynamic responses of real per-capita GDI (real GDP corrected by terms-of-trade fluctuations), which is our second measure of economic activity, to the different external shocks is shown in Figure 3. The reason to look at GDI as an alternative measure of activity is that a significant part of the discussion on the importance of commodity price fluctuations on macroeconomic stability in low-income countries is related to the impact of these price fluctuations on these countries' income and their ability to honor their debt obligations or buy necessary imported capital goods. It is apparent that the IRF reported in the different panels of the Figure 3 are very similar to those reported on Figure 2 with two exceptions. First, as expected, the impact of a commodity price shock is larger and more protracted than before, reaching a peak of 1.6 percent four years after the initial shock. Second, the aid shock induces an initial 1 percent decline in real GDI, which turns 
into a 0.5 percent increase in year 2. This pattern was also present in Panel G of Figure 2, but in that case the initial negative effect was not significant, and the subsequent positive effect was larger. A possible explanation for this pattern is that the initial increase in aid may trigger a real appreciation of the local currency, which induces an initial decline in real GDI.

Overall, the dynamic responses shown in Figure 2 demonstrate that most external shocks have a significant and correctly signed impact on real activity. The magnitudes of the effects lie between 1 and 5 percent of real per capita GDP at their peaks. These magnitudes are clearly economically meaningful when compared with a one percent average trend in log real per-capita GDP among the countries in the sample. Similar conclusions are obtained when looking at the impact of these shocks on real per-capita GDI. However, the fact that external shocks have a real economic impact that is economically significant does not necessarily mean that they are the main factor behind the volatility of output in low-income countries. In the next section, we perform a variance decomposition exercise to assess the relative importance of these shocks for output fluctuations.

\subsection{Can external shocks account for the variance of output?}

We perform a standard variance decomposition exercise for the variables contained in the VAR to determine the ability of external shocks as a whole to explain GDP and GDI fluctuations at different horizons, and the relative importance of each different shock. The results of this decomposition are reported in the two panels of Table 2.

Panel A presents the variance decomposition of the forecast error of (log) GDP. The first two columns of the table show the fraction of the one, five, and ten year ahead forecast error that can be explained by all external shocks versus internal factors. For practical purposes, the variance of the 10 year ahead forecast error is almost identical to the unconditional variance of real GDP. So, this row shows the fraction of the total variance of real GDP and GDI that can be accounted by each type of shock. ${ }^{9}$ Columns 1 and 2 clearly show that external shocks can account for only a small fraction of the variance of the forecast error at all horizons. Their relative importance, vis-à-vis internal factors, increase with the forecast horizon, but even in the long run, they account for only about 11 percent of the total output variance. The results suggest, therefore, that external shocks are not the main factor driving fluctuations in real activity in low-income countries. Although their

\footnotetext{
${ }^{9}$ There is almost no change in the decomposition between the variance of the 10 and 20 year ahead forecast errors.
} 
impact is statistically and economically significant, internal factors are the ones that play the main role.

The second half of the table (Columns 3 to 9) looks into the relative importance of each external shock. The different columns show the fraction of the variance of the forecast error of real GDP explained by external shocks that can be accounted by the different shocks included in this category. The table shows that, in the short run, most of this variance (93 percent) can be explained by shocks to international conditions (GDP of high-income countries and real interest rate), real aid flows, and Climatic disasters. In the long run however, commodity price shocks are the most important exogenous source of fluctuations (37\%), followed by aid shocks (25\%), and climatic disasters (14\%). Geological disasters do not play a relevant role at any frequency.

Panel B shows the same variance decomposition exercise for the forecast error of real per capita GDI. External shocks play a slightly more important role in this case, accounting for about 16 percent of the long run variance of real GDI, which is largely due to a much more important role played by commodity price shocks, as it can be seen in the second half of the table. The overall picture is however largely the same as in the case or real per capita GDP. It is internal factors the ones that account for most of the variance of real activity.

\section{Robustness}

The results reported in the previous section were obtained under a series of assumptions regarding identification, specification, choice of variables, etc. In this section we test the robustness of the results to these specific choices.

Table 3 summarizes the results of this robustness analysis. The different panels of the table report the results of the variance decomposition of the forecasting error of real GDP per capita 1, 5, and 10 years ahead. The first six panels show the results obtained for different variations of the benchmark specification. In the specification of Panel 1 we use only one lag instead of the three used in the benchmark specification. In Panels 2 and 3 we change the order of the variables in the exogenous block, which implies a change in the identification assumptions regarding the contemporaneous causal order. In Panel 2 we put the commodity prices before the international variables, and in Panel 3 we put it after both the real GDP of high-income countries and the 
international interest rate. In Panel 4 we assume that only the common component of commodity prices (as captured by their average across LIC) affects the international variables (in the same order as the benchmark specification), while in Panel 5 we assume that the commodity price indexes of LIC do not have any effect on the international variables at any frequency. The specification in Panel 6 is identical to the benchmark, except that real per capita aid flows are not included in the VAR. Panels 7 and 8 report the results obtained under the benchmark specification, but using different samples. In Panel 7 the sample includes only post-1973 data. The reason is to determine whether there is any difference between the pre and post oil shock periods. Under a similar logic, the sample used in Panel 8 includes only non oil exporter countries. The results shown in Panel 9 were obtained under the benchmark specification, but using the broad terms-of-trade measure described in Section 2 instead of the Deaton-Miller terms-of-trade index. Finally, panels (10) and (11) report the results obtained estimating the system in first differences instead of levels, and using the Deaton-Miller and the broad terms-of-trade indexes respectively. In these last two cases, the model did not include a trend.

The table clearly shows that the main results of the paper are extremely robust. Regardless of the identification assumption, the details of the specification, or the specific choice of variables, external shocks are able to account only for a small fraction of the variance of output that never exceeds 15 percent. In fact, if anything, the benchmark specification is among the most favorable to external shocks as a source of fluctuations.

Including only one lag, as in Panel 1 reduces significantly the ability of external shocks to account for output volatility. ${ }^{10}$ As expected, Panels 2 and 3 show that the ordering within the exogenous block does not affect the importance of this group of variables as a whole. The relative importance of commodity prices and international variables vary a little with the ordering, but the overall ranking across exogenous shocks is not affected. The same is true for the results reported in panels (4) and (5). Panel 6 shows that excluding aid flows increases the relative importance of the international variables. The fact that these variables now capture part of the impact of aid shocks speaks to the correlation between aid flows and the economic conditions of rich countries. Interestingly, the results reported in Panel 8 show a decline in the relative importance of commodity

\footnotetext{
${ }^{10}$ Although not reported, the IRF obtained for this case strongly suggest that the model with one lag is misspecified, as most of the series have not returned to their baseline level after 20 years.
} 
prices and an increase in the role played by interest rate in the short run, and aid fluctuations in the long run during the post 1973 period. This suggests that at least part of the explanatory power of commodity prices came from the first oil shock episode, ${ }^{11}$ but also that the relative importance of international capital markets has increased in the last 25 years for this group of countries with limited access to these markets. In the short run this manifests as a larger role of the international real interest rate, while in the long run it manifests as an increased importance of aid fluctuations. The reason is that, as we will document below, aid flows are highly responsive to changes in the international interest rate. The results obtained for the sample of non-oil exporters are very similar to the benchmark, which is not surprising because the initial sample contained only 3 oil exporters (Angola, Congo, and Nigeria). Panel 9 shows that using a broad terms-of-trade index instead of the Deaton-Miller commodity price based index reduces the fraction of output variance explained by the external shocks in 25 percent, and that this reduction is largely the result of the smaller role of terms-of-trade shocks, even in the long run. This is somewhat surprising, as we may have expected this broader index to capture a larger set of fundamental relative price shocks than those reflected in the DM index. However, the results suggest that, at least for this group of countries, commodity prices are the main source of relevant relative price fluctuations. Finally, panels (10) and (11) show that estimating the model assuming that the variables are first-difference-stationary instead of trend-stationary does not make a significant difference in the ability of external shocks to account for output volatility, independently of the specific measure of terms of trade used in the analysis, ${ }^{12}$ although the relative importance of the GDP of rich countries is larger in these cases. These findings are in line with those of Ahmed (2003), who found that external shocks played a small role explaining fluctuations in a group of six emerging markets (Argentina, Brazil, Chile, Colombia, Mexico, and Venezuela) using a specification in first differences.

\footnotetext{
${ }^{11}$ Similar results are obtained when dummies for the years of the different oil shocks $(1973,1979,1986$, and 1990) are included in the VAR.

${ }^{12}$ Of course, in this case the variance decomposition refers to the variance of the growth rates instead of the log deviations from trend.
} 


\section{$6 \quad$ Extensions}

\subsection{External shocks, government expenditure, and debt}

It is frequently claimed among policymakers that an important aspect of the link between external shocks and economic performance in low-income countries results from the effect of these shocks (specially commodity price shocks) on government expenditure, on a country's ability to serve its debt obligations, and on its level of indebtedness. To explore this possibility we follow Deaton and Miller (1996) and add to the vector of endogenous variables $y$ the following variables: real consumption $(C O N S)$, investment $(I N V)$, and government expenditure $(G O V)$ (all real per capita in logs). So, the vector $y$ in equation (1), corresponds now to $y=(G D P, C O N S, I N V, G O V)^{\prime}$. We do not include net exports $(N X)$ explicitly in the system because they can take negative values, which would make the estimation in logs unfeasible. Notice that because of the exclusion of net exports and the estimation in logs, there is not a trivial co-integration relationship among the components of $y$. To recover the decomposition of output that we show in the IRF below we use the average shares of each component in the sample, and compute net exports $N X$ as a residual. ${ }^{13}$

The results of this exercise are reported in Figure 4, which shows the dynamic responses of output, government expenditure, and the current account (net exports) to each of the exogenous shocks. As, by definition, the change in the current account is equal to the change in the capital account plus the change in reserves, the evolution of net exports give us a sense of what is happening with the net foreign position of a country.

The figure shows that government expenditure usually moves in tandem with total output. So, shocks that tend to increase real activity tend to increase government expenditure. To the extent that government expenditure is used to provide valuable social services, the results suggest that negative external shocks will affect the ability of the government to provide such services. Also, as long as the increase in government expenditure is not purely financed with tax revenue, government debt may increase as a result of a positive shock. Interestingly, the different panels of Figure 4 show that, although government expenditure always moves in the same direction as total output, the response of government expenditure to a shock vis-à-vis total output is much smaller in the case of natural disasters. This finding provides some evidence that government may try, at least

\footnotetext{
${ }^{13}$ The shares used in the figure are 0.78 for consumption, 0.12 for investment, and 0.23 for government consumption.
} 
partially, to compensate for the negative impact of these disasters.

Regarding the impact of the different shocks on the current account, the figure suggests that, with the exception of Geological disasters, the current account tends to go to surplus (deficit) as a result of a negative (positive) shock, in other words, in this countries the current account is countercyclical: they borrow in good times and "lend" (increase their position) in bad times. In this regard, these countries do not seem to behave differently from emerging markets, which have been documented to have a highly procyclical access to capital markets (see Agiar and Gopinath, 2004). It is important to keep in mind that the dynamic response of net exports was computed as a residual from a linear approximation using the average shares of the other GDP components, so it also captures inaccuracies in the approximation and in the shares used. However, given the magnitudes observed in the IRFs, it is unlikely that the explicit consideration of these errors could reverse the conclusion about the cyclicality of the current account. Overall, these findings suggest that negative external shocks are not directly linked with significant increases in the level of external debt of low-income countries. On the contrary, these countries seem to accumulate debt while in good times. Of course, the results also imply that, during bad times, these countries are not able to borrow, and most likely have to serve their debt obligations with a reduced level of output and income. It is in this regard that negative external shocks may put these countries under a lot of stress, but, as mentioned above, this situation is not different from that experienced by emerging markets, so, the evidence does not support any structural difference between these groups of countries in this regard.

\subsection{The determinants of aid}

Much has been recently discussed on academic and policy circles about the adequacy of the level of aid to low-income countries and its effectiveness (see for example, Burnside and Dollar, 2000; Sachs et al., 2004; and Easterly et al., 2004). Despite this recent interest on the effects of aid, little is known about the determinants of aid flows. ${ }^{14}$ Here we provide some new evidence on this regard by showing how aid flows respond to the different external shocks that affect low-income countries. This can be seen in Figure 5.

The different impulse-response functions reported in the figure show that both, supply and

\footnotetext{
${ }^{14}$ Some recent papers exploring this issue include Neumeyer (2003) and Odedokun and Round (2003).
} 
demand factors affect the flows of aid to low-income countries. On the supply side, Panel 1 shows that a one-percent-increase in $G D P H$ (one standard deviation shock) induces a significant 4 percent increase in $A I D$. On the demand side, Panels 2 and 7 show that both, an improvement on the commodity prices and a positive endogenous shock, result in a decline in aid flows. Surprisingly, aid flows do not seem to respond significantly to the occurrence of natural disasters. A Geological disaster seems to be associated, if anything, with a decline in aid flows. Climatic disasters do not seem to affect these flows, and only in the case of human disasters we observe a large positive, albeit not statistically significant, reaction of aid flows.

Table 4 presents the variance decomposition of the forecast error of log real per-capita aid at different horizons. Similarly to the case of real GDP per-capita, the table shows that most of the variance of aid is accounted for its own shock. This seems to indicate that most of the variability of aid is the result of purely idiosyncratic reasons unrelated to the state of the world economy or the economic performance of the targeted countries. Among the determinants of aid, the intuition suggested by the IRF is confirmed; the state of the world economy (output and real interest rates) and changes in a country's commodity prices are the most important observable determinants of aid flows. The incidence of natural disasters and the performance of the target countries do not play large role (except for an unusually large role of Geological disasters in the short run).

\subsection{Openness, Indebtedness, and Institutions}

Our analysis so far has assumed that the impact of external shocks is identical across low-income countries. Of course, this assumption can be challenged on a number of grounds. In particular, it is reasonable to think that, even among low-income countries, the impact of external shocks depends on specific country characteristics. In this section, we briefly explore the role of three such characteristics: the level of trade openness, indebtedness, and the quality of institutions. We do not consider other characteristics that are likely to be important, such as the level of financial openness (as measured by the openness of the capital account) or the degree of local financial development because of their limited variation within our sample. ${ }^{15}$ Still, the variability of the characteristics

\footnotetext{
${ }^{15}$ The interquartile range of variation of the Chinn and Ito (2002) measure of capital account openness lies between -1.1 and -0.05 , compared with -1.1 and 1.2 for the whole sample of countries for which the measure is available. In the case of the measures of local financial development, the interquartile range of variation of private credit as a fraction of GDP lies only between 7 and 22 percent. In fact, the 90 th percentile starts at only 30 percent. This limited variation makes this sample uninteresting for the exploration of these issues.
} 
considered is still limited in our sample, so we should in principle not expect large differences among groups of countries. Also, we estimate the impact of each characteristic separately to keep the number of parameters and degrees of freedom at bay. Although existing studies have also not considered a full set of interactions (see Broda, 2004, for an example) using this stepwise analysis we cannot be completely sure that the differential effects associated with a particular characteristic are not actually due to a different characteristic that is correlated with it. Nevertheless, as it will be shown below, some suggestive differences emerge that indicate that some specific factors may affect a country's vulnerability to external shocks and seem to confirm some of the intuition on the role of these characteristics.

By increasing the relative importance of trade as a fraction of GDP, trade openness can make a country more vulnerable to fluctuations in the international demand or prices of its main products. It also may reduce the degree of import substitution, exposing countries to fluctuations in the international prices of its main import products and reducing the degree of diversification. We explore the impact of openness on the dynamic response of output to external shocks by interacting with an indicator variable (that takes the value 1 if a country is open in a given year) all the variables on the right hand side of the output equation of the benchmark specification (the last equation in the system represented by equation (1)). The dummy variable is constructed using the liberalization dates compiled by Sachs and Warner (1995) and extended by Wacziarg and Welch (2003). The results of this exercise are reported in Figure 6, which compares the dynamic responses of the real per capita GDP of open and closed low-income countries to each external shock. In general, trade openness does not seem to affect much the dynamic response of output to external shocks, and only three interesting differences emerge. First, the initial impact of commodity price shocks is larger in open low-income countries, which is consistent with a higher exposure resulting from the higher relative importance of trade in these countries, but their persistence is shorter than in closed low-income countries. This difference in persistence seems to indicate that, although less exposed initially, closed economies probably lack appropriate mechanisms to deal with the impact of these shocks. Second, the impact of a shock to the international real interest rate is larger in open economies, which is consistent with these economies being more synchronized with the international business cycle. Finally, an aid shock seems to have a larger impact on closed economies, suggesting that aid flows play a larger role on countries that are only partially integrated with the rest of the 
world. Overall, these dynamic responses provide suggestive evidence that is consistent with some of the expected effects of trade openness on a country's vulnerability to external shocks.

Highly indebted poor countries (HIPC) are often considered to be especially vulnerable to the effect of exogenous shocks (see IMF, 2002). The intuition is that the need to serve a large stock of debt reduces considerably the ability of these countries to smooth the impact of a negative shock that simultaneously reduces revenue and increases the pressure for countercyclical fiscal policy. To study the differential impact of shocks on HIPC we add to our main specification the interaction between a dummy variable that indicates whether a country belongs to the HIPC group and the rest of the variables in the system. Importantly, we do this for the two equations corresponding to the lower block of the system only $(A I D$, and $G D P)$. That is, we assume that only the dynamic responses of aid and output are different in HIPC countries. The dynamic responses of output to the different external shocks in HIPC and non-HIPC low-income countries are compared in Figure 7. The most remarkable feature of this figure is that it shows that the response of output to the world business cycle, commodity price, and interest rate shocks is larger and more persistent in HIPC countries (which represent 76 percent of the observations). Interestingly, the impact of aid shocks is not larger among these countries. The results therefore seem to confirm then that the impact of exogenous shocks is larger in HIPC countries. ${ }^{16}$

The importance of institutions for output volatility has also been a source of recent debate (see Rodrick, 1999; Acemoglu et al. 2002, and Raddatz, forthcoming; among others). According to this literature, countries with good institutions are better able to deal with the distributional consequences of exogenous shocks and also tend to follow more sound macroeconomic policies when facing exogenous contingencies. At a more general level, a better institutional environment may provide the ground for the development of complex contract arrangements that deal with the uncertainty associated with these shocks. We attempt to address this issue by comparing the dynamic responses to shocks of countries with institutions above and below the sample median (according to their average rule of law indicator). Admittedly, our sample offers limited variation on the in-

\footnotetext{
${ }^{16}$ Of course, our simple specification is not able to control for possible reverse causality problems. It may well be argued that countries become highly indebted precisely because the impact of exogenous shocks is larger. However, addressing this type of endogenous amplification is beyond the scope of this paper and, to the best of our knowledge, it has not even been treated in the panel time-series literature. The procedure we have used is standard in the literature (see Broda, 2002), and the relationship between the HIPC category and the responses is correct, at least from a reduced form perspective.
} 
dicators of institutional quality, as most countries included tend to lie below the world average. Nevertheless, this problem stacks the cards against finding any interesting differences across this dimension. As in the previous cases, we add a series of interaction terms to the benchmark specification to allow the dynamic response of output and aid flows to shocks to vary across countries with law and order indicators above and below the median. The reason to allow aid flows to vary across levels of institutional quality is the recent emphasis of multilateral institutions as the World Bank on measures of institutional quality to determine aid flows (see Kraay, 2005), but similar results are obtained when only the dynamics of output are allowed to vary across groups. The results are reported in Figure 8. The figure suggests that, at least in the case of shocks to the world business cycle and commodity prices, the output effect is larger in countries with law and order indicators below the median, but the reverse is true with respect to shocks to the international real interest rate. ${ }^{17}$ Surprisingly, in this sample aid shocks do not seem to have a larger impact in countries with relatively better institutions, which goes against the findings of Burnside and Dollar (2000). Of course, as previously mentioned, the degree of institutional variation in our sample is smaller than in Burnside and Dollar (2000), and also the specific measure of institutions used is different, so the results are not directly comparable. In addition, the dynamic response presented in Panel G corresponds to an aid shock that is orthogonal to changes in the world business cycle. As we also find that countries with better institutions are more benefited by an improvement in the world business cycle, and that aid flows are positively correlated with this cycle, one way of reconciling our findings with Burnside and Dollar's is that their result shows, in reduced form, that countries with better institutions are better able to take advantage of positive international conditions.

Summing up, the results shown in this section suggest that some specific country characteristics can play a role in the amplification of the impact of external shocks, and give partial support to some of the hypothesis that have been raised regarding the role of some of these characteristics. These results however have to be taken with caution because, as it is common in the literature, the problem of endogeneity between the shape of the dynamic response and country characteristics has not been addressed; because the different characteristics have been considered in isolation, and because of the limited variation in some of the characteristics analyzed.

\footnotetext{
${ }^{17}$ Geological disasters also appear to have a larger impact on countries with better institutions. We do not highlight this result because the impact of geological disasters have never appeared significant in any specification.
} 


\section{Conclusion}

This paper quantified the absolute and relative importance of a broad set of external shocks for output fluctuations in low-income countries. In this respect, the main objective of this paper has been to test whether the importance typically attributed to external shocks in policy circles is actually borne out by the data. The general picture that emerges is that although external shocks have economically meaningful effects on real activity, especially when compared with the average economic performance of low-income countries, they account for only a small fraction of the volatility of these countries' real GDP. The economic instability experienced by low-income countries is therefore largely the result of internal factors.

Without further (and strong) identification assumptions, we can only speculate about what are the most important internal causes of economic instability, but the episodes of inflation, real exchange overvaluation, and high levels of public deficit experienced by these countries suggest that economic management is probably an important part of the story. However, the importance of political instability and violent conflict should not be overlooked within this sample. Although identifying the separate role played by these different internal factors is a difficult task, the results of this paper suggest that future research in that area may go a long way into understanding the causes of instability in low-income countries.

From a policy perspective, our results suggest that the emphasis on external shocks as a source of economic instability in low-income countries is misplaced. A standard criticism to previous studies that documented a small role for some external shocks, such as terms of trade and interest rate fluctuations, was that they had left out some other important external sources of instability like natural disasters and aid volatility. We have shown that, although these other sources of exogenous shocks play a role and have important quantitative effects, their inclusion does not increase significantly the role played by external shocks as a whole. Of course, this does not imply that exogenous shocks should be completely disregarded. We have shown that large fluctuations in commodity prices and natural disasters have non-trivial quantitative effects that merit attention. But the belief that the stabilization of exogenous shocks would significantly reduce the macroeconomic volatility of these countries is not borne out by the data.

Another aspect of policy that is related to our results is that of insurance against external shocks. 
The large role played by internal factors implies that exogenous contingencies may have limited power to smooth output fluctuations. Also, the importance of the state of the world economy for the performance of these countries implies that there is a sizable fraction of the risk factors that is uninsurable. Moreover, even without accounting for the correlation between commodity price shocks and the state of the world economy, the high persistence of these shocks raises some questions regarding whether the optimal response is insurance or adjustment. There is however an alternative reading of the results. They also imply that, to a large extent, output fluctuations are not determined by factors that countries cannot control without large changes in their productive structures or their position in the international economy. 


\section{References}

[45] Albala-Bertrand, J. M., 1993. "Political economy of large natural disasters: With special reference to developing countries", Oxford University Press, Clarendon Press.

[45] Acemoglu D., Johnson S., Robinson J., Thaicharoen Y., 2003. "Institutional causes, macroeconomic symptoms, volatility, crises and growth", Journal of Monetary Economics, 50, 49-123.

[45] Aghion, P., G. M. Angeletos, A. Banerjee, and K. Manova, 2005. "Financial development and the cyclical composition of investing", Mimeo, Harvard University.

[45] Aguiar, M., and G. Gopinath, 2004, "Emerging Market Business Cycles: The Cycle is the Trend," Federal Reserve Bank of Boston Working Paper 04-4.

[45] Broda, C., 2001. "Coping with terms-of-trade Shocks: Pegs versus Floats", American Economic Review, v 91 (2), pp 376-80.

[45] Broda, Christian, 2004. "terms-of-trade and Exchange Rate Regimes in Developing Countries," Journal of International Economics, 63 (1), 31-58.

[45] Barro, Robert J, 1991. "Economic Growth in a Cross Section of Countries," The Quarterly Journal of Economics, vol. 106(2), 407-43.

[45] Burnside, C. and D. Dollar, 2000. "Aid, Policies, and Growth," American Economic Review, $90(4), 847-868$.

[45] Calvo, G., 1998, "Capital Flows and Capital-Market Crises: The Simple Economics of Sudden Stops" Journal of Applied Economics, 1 (1), 35-54.

[45] Chinn, Menzie, and Hiro Ito, 2002, "Capital account liberalization, institutions and financial development: Cross Country evidence", NBER Working Paper 8697.

[45] Christiano, L., M. Eichenbaum, and C. Evans, 1998. "Monetary Policy Shocks: What Have We Learned and to What End?," NBER Working Papers 6400.

[45] Collier, Paul, and Jan Dehn, 2001. "Aid, Shocks, and Growth," Policy Research Working Paper Series 2688, The World Bank. 
[45] Collier, Paul and Willem Gunning, 1999. "Trade Shocks in Developing Countries", Clarendon Press, Oxford, 1999, Paul Collier, Jan Willem Gunning and Associates eds. Volume 1: Africa.

[45] Deaton, Angus and Miller, Ron, 1996. "International Commodity Prices, Macroeconomic Performance and Politics in Sub-Saharan Africa," Journal of African Economies, vol. 5(3), 99-191.

[45] Dehn, J., 2000. "The Effects on Growth of Commodity Price Uncertainty and Shocks," Policy Research Working Paper Series 2455, The World Bank.

[45] Easterly, W., M. Kremer, L. Pritchett, and L. Summers, 1993. "Good policy or good luck?: Country growth performance and temporary shocks," Journal of Monetary Economics, 32 (3), 459-483.

[45] Easterly, W., R. Levine, and D. Roodman, 2004. "New Data, New Doubts: A Comment on Burnside and Dollar's "Aid, Policies, and Growth,"” American Economic Review, 94 (2).

[45] EM-DAT, The OFDA/CRED International Disaster Database, www.em-dat.net, Université Catholique de Louvain, Brussels, Belgium.

[45] Enders, W., 1995. "Applied econometric time series", Series in Probability and Mathematical Statistics. New York; Chichester, U.K. and Toronto: Wiley.

[45] Froot, K. and Kenneth Rogoff, 1996. "Perspectives on PPP and Long-Run Real Exchange Rates," NBER Working Papers 4952.

[45] Hoffmaister, A., J. Roldos, and P. Wickham, 1998. "Macroeconomic Fluctuations in SubSaharan Africa," IMF Staff Papers, vol. 45(1).

[45] IMF, 2003, "Fund Assistance for Countries Facing Exogenous Shocks", Policy Development and Review Department, International Monetary Fund.

[45] IMF, 2002. "The Enhanced HIPC Initiative and the Achievement of Long-Term External Debt Sustainability", International Monetary Fund, and International Development Agency.

[45] Jones, C. I., 1997. "On the Evolution of the World Income Distribution," Journal of Economic Perspectives, 11 (3), 19-36. 
[45] Kose, M. A. and Raymond Riezman, 2001. "Trade Shocks and Macroeconomic Fluctuations in Africa," Journal of Development Economics, 65, 55-80.

[45] Levin, A., C. Lin, and J. Chu, 2002. "Unit root tests in panel data: asymptotic and finitesample properties," Journal of Econometrics, 108 (1), 1-24.

[45] Laursen, S. and L. Metzler, 1950, Flexible exchange rates and the theory of employment. Review of Economics and Statistics, 32, 281-299.

[45] Mendoza, E., 1995. "The Terms of Trade, the Real Exchange Rate, and Economic Fluctuations," International Economic Review, vol. 36(1), 101-37.

[45] Nelson Charles, and Charles Plosser, "Trends and Random Walks in Macroeconomic Time Series: Some Evidence and Implications", Journal of Monetary Economics, 10, (1982), 130-62.

[45] Neumeyer, E., 2003. "The determinants of aid allocation by regional multilateral development banks and United Nations agencies", International Studies Quarterly, 47(1), 101-122.

[45] Odedokun, M., 2003. "Analysis of deviations and delays in aid disembursements", Journal of Economic Development, 28 (1), 137-169.

[45] Odedokun, M. and J. Round, 2003, "Aid effort and its determinants", WIDER Discussion Paper 2003-3.

[45] Otero, R. C., and Ricardo Martí, 1995. "The Impact of Natural Disasters on Developing Economies: Implications for the International Development and Disaster Community", in Disaster Prevention for Sustainable Development, Economic Policy Issues, Munasinghe and Clarke eds., IDNDR and the World Bank.

[45] Pakes, A. and Zvi Griliches, 1984. "Estimating Distributed Lags in Short Panels with an Application to the Specification of Depreciation Patterns and Capital Stock Constructs," Review of Economic Studies, vol. 51(2), 243-62.

[45] Pesaran, M. Hashem \& Smith, Ron, 1995. "Estimating long-run relationships from dynamic heterogeneous panels," Journal of Econometrics, vol. 68(1), 79-113. 
[45] Raddatz, C., Forthcoming. "Liquidity needs and vulnerability to financial underdevelopment", Journal of Financial Economics.

[45] Rodrick, D., 1999, "Where Did All the Growth Go? External Shocks, Social Conflict and Growth Collapses," Journal of Economic Growth.

[45] Sachs, J., and A. Warner, 1995. "Economic reform and the process of global integration", Brooking Papers on Economic Activity, 1-118.

[45] Sachs, J., J. McArthur, G. Schmidt-Traub, M. Kruk, C. Bahadur, M. Faye, and G. McCord, 2004. "Ending Africa's Poverty Trap", Brooking Papers on Economic Acitivity.

[45] Skidmore, M., and Hideki Toya, 2002. "Do Natural Disasters Promote Long-Run Growth?," Economic Inquiry, vol. 40(4), 664-687.

[45] UNCTAD, 2002. "The least developed countries report 2002: Escaping the Poverty Trap", United Nations Conference on Trade and Development.

[45] Uribe, M., and V. Yue, 2004. "Country spreads and emerging countries: who drives whom?," NBER Working Paper 10018.

[45] Wacziarg, R., and K. Horn Welch, 2003. "Trade Liberalization and Growth: New Evidence", NBER Working Paper 10152.

[45] World Bank, 2000. "World Development Report 2000: Attacking Poverty". New York: Oxford University Press.

[45] World Bank, 2004. "Global Monitoring Report. Policies and Actions for Achieving the Mileium Development Goals and Related Outcomes", The International Bank for Reconstruction and Development, Washington, D.C. 


\section{Table 1: Sample of countries included in the analysis and summary statistics}

The table shows some summary statistics for each of the 40 low income countries included in the analysis (top panel) and compares them with other income groups (bottom panel). For each country (income group), column (1) shows the sample period used in the paper (number of countries included in each group); columns (2) and (3) show the average and standard deviation of the growth of real GDP (PPP adjusted) during the sample period; columns (4) to (7) present similar statistics for the Deaton-Miller commodity based terms of trade index (see Deaton and Miller (1996)) and the standard terms of trade index (ratio of exports and import prices from PennWorld Tables 6.1); column (8) displays the average value of aid flows as a fraction of gross domestic income (from the World Bank WDI); columns (9) and (10) show the average and standard deviation of the growth rate of per-capita aid flows (in constant US\$); columns(11) to (13) present the average number of Geological, Climatic, and Human disasters per year computed as the total number of each disaster divided by the number of years in the sample. Figures in the bottom panel correspond to the average across all countries in each income group.

\begin{tabular}{|c|c|c|c|c|c|c|c|c|c|c|c|c|c|}
\hline Country & Sample period & $\begin{array}{l}\text { Average real } \\
\text { GDP growth }\end{array}$ & $\begin{array}{c}\text { Standard } \\
\text { deviation real } \\
\text { GDP growth }\end{array}$ & $\begin{array}{l}\text { Average } \\
\text { growth DM } \\
\text { index }\end{array}$ & $\begin{array}{l}\text { Std deviation } \\
\text { growth DM } \\
\text { index }\end{array}$ & $\begin{array}{c}\text { Average } \\
\text { growth Terms } \\
\text { of Trade index }\end{array}$ & $\begin{array}{c}\text { Standard } \\
\text { Deviation } \\
\text { growth Terms } \\
\text { of Trade index }\end{array}$ & $\begin{array}{c}\text { Average aid as } \\
\text { a fraction of } \\
\text { GNI }\end{array}$ & $\begin{array}{c}\text { Average } \\
\text { growth of real } \\
\text { per capita aid }\end{array}$ & $\begin{array}{c}\text { Standard } \\
\text { deviation of } \\
\text { real per capita } \\
\text { aid growht }\end{array}$ & $\begin{array}{c}\text { Average } \\
\text { number of } \\
\text { large } \\
\text { Geological } \\
\text { disasters per } \\
\text { year }\end{array}$ & $\begin{array}{c}\text { Average } \\
\text { number of } \\
\text { large Climatic } \\
\text { disasters per } \\
\text { year }\end{array}$ & $\begin{array}{c}\text { Average } \\
\text { Number of } \\
\text { large } \\
\text { Humanitarian } \\
\text { disasters per } \\
\text { year }\end{array}$ \\
\hline & (1) & (2) & (3) & (4) & (5) & (6) & (7) & (8) & (9) & (10) & (11) & (12) & (13) \\
\hline Angola & 1985-1996 & -0.028 & 0.160 & -0.064 & 0.277 & -0.022 & 0.202 & 6.466 & 0.116 & 0.410 & 0.000 & 0.333 & 0.000 \\
\hline Bangladesh & 1971-1997 & 0.015 & 0.047 & -0.037 & 0.218 & -0.013 & 0.264 & 5.704 & 0.111 & 0.592 & 0.000 & 1.222 & 0.074 \\
\hline Benin & 1965-1997 & 0.000 & 0.038 & -0.014 & 0.168 & -0.013 & 0.136 & 8.978 & 0.020 & 0.228 & 0.000 & 0.333 & 0.000 \\
\hline Burkina Faso & 1965-1997 & 0.011 & 0.036 & -0.011 & 0.178 & 0.004 & 0.128 & 11.007 & 0.054 & 0.171 & 0.000 & 0.303 & 0.091 \\
\hline Burundi & 1965-1997 & 0.002 & 0.081 & -0.015 & 0.256 & -0.022 & 0.313 & 14.035 & 0.028 & 0.291 & 0.000 & 0.000 & 0.000 \\
\hline Cameroon & 1965-1997 & 0.004 & 0.070 & -0.010 & 0.108 & -0.005 & 0.194 & 4.385 & 0.016 & 0.309 & 0.030 & 0.030 & 0.061 \\
\hline Central African Republic & 1965-1997 & -0.027 & 0.067 & -0.014 & 0.234 & -0.026 & 0.238 & 12.684 & -0.013 & 0.262 & 0.000 & 0.061 & 0.000 \\
\hline Chad & 1965-1997 & -0.009 & 0.140 & -0.013 & 0.191 & -0.011 & 0.129 & 10.715 & 0.031 & 0.319 & 0.000 & 0.394 & 0.121 \\
\hline Congo, Dem. Rep. & 1965-1997 & -0.038 & 0.070 & -0.014 & 0.154 & -0.003 & 0.174 & 3.719 & -0.024 & 0.326 & 0.000 & 0.061 & 0.000 \\
\hline Congo, Rep. & 1965-1997 & 0.026 & 0.078 & 0.024 & 0.278 & -0.019 & 0.188 & 8.117 & 0.025 & 0.458 & 0.030 & 0.030 & 0.000 \\
\hline Cote d'Ivoire & $1965-1997$ & 0.002 & 0.051 & -0.035 & 0.116 & -0.018 & 0.166 & 4.414 & 0.000 & 0.309 & 0.000 & 0.000 & 0.000 \\
\hline Ethiopia & 1981-1997 & -0.007 & 0.086 & -0.011 & 0.199 & 0.003 & 0.208 & 10.686 & 0.038 & 0.283 & 0.000 & 0.588 & 0.235 \\
\hline Gambia, The & 1966-1997 & -0.001 & 0.034 & 0.000 & 0.201 & -0.017 & 0.138 & 20.257 & 0.017 & 0.451 & 0.000 & 0.094 & 0.063 \\
\hline Ghana & 1965-1997 & 0.013 & 0.072 & -0.025 & 0.099 & -0.010 & 0.182 & 5.679 & 0.034 & 0.350 & 0.000 & 0.061 & 0.030 \\
\hline Guinea & 1986-1997 & 0.016 & 0.013 & -0.033 & 0.199 & -0.041 & 0.098 & 11.649 & 0.026 & 0.234 & 0.000 & 0.000 & 0.000 \\
\hline Guinea-Bissau & 1973-1997 & 0.034 & 0.156 & 0.001 & 0.171 & -0.020 & 0.190 & 44.628 & 0.354 & 1.212 & 0.000 & 0.000 & 0.120 \\
\hline Haiti & 1967-1997 & 0.025 & 0.094 & 0.004 & 0.257 & -0.002 & 0.166 & 7.648 & 0.084 & 0.423 & 0.000 & 0.323 & 0.032 \\
\hline Honduras & 1965-1997 & 0.006 & 0.039 & -0.005 & 0.128 & -0.003 & 0.090 & 5.951 & 0.038 & 0.283 & 0.030 & 0.333 & 0.000 \\
\hline India & 1965-1997 & 0.026 & 0.033 & -0.014 & 0.086 & -0.001 & 0.103 & 1.096 & -0.029 & 0.297 & 0.030 & 1.030 & 0.000 \\
\hline Indonesia & $1967-1997$ & 0.049 & 0.019 & 0.007 & 0.185 & 0.058 & 0.146 & 1.986 & -0.026 & 0.227 & 0.000 & 0.065 & 0.000 \\
\hline Kenya & 1965-1997 & 0.013 & 0.059 & -0.020 & 0.184 & -0.004 & 0.097 & 7.045 & 0.001 & 0.267 & 0.000 & 0.212 & 0.030 \\
\hline Lesotho & 1975-1997 & 0.014 & 0.065 & -0.019 & 0.119 & -0.021 & 0.126 & 12.346 & 0.008 & 0.129 & 0.000 & 0.217 & 0.000 \\
\hline Madagascar & 1965-1997 & -0.010 & 0.028 & 0.000 & 0.135 & -0.014 & 0.084 & 7.807 & 0.030 & 0.257 & 0.000 & 0.606 & 0.000 \\
\hline Malawi & 1965-1997 & 0.015 & 0.085 & -0.012 & 0.099 & -0.010 & 0.103 & 16.884 & 0.011 & 0.276 & 0.030 & 0.212 & 0.061 \\
\hline Mali & $1967-1997$ & 0.006 & 0.056 & -0.014 & 0.189 & -0.008 & 0.092 & 15.786 & 0.040 & 0.245 & 0.000 & 0.194 & 0.065 \\
\hline Mauritania & $1965-1997$ & -0.010 & 0.075 & -0.025 & 0.104 & -0.005 & 0.119 & 21.206 & 0.048 & 0.430 & 0.000 & 0.303 & 0.061 \\
\hline Mozambique & 1980-1997 & -0.011 & 0.074 & 0.001 & 0.095 & -0.063 & 0.113 & 31.929 & 0.105 & 0.405 & 0.000 & 0.611 & 0.167 \\
\hline Nepal & 1965-1997 & 0.017 & 0.035 & -0.027 & 0.198 & 0.002 & 0.035 & 6.949 & 0.054 & 0.217 & 0.091 & 0.182 & 0.000 \\
\hline Nicaragua & 1965-1997 & -0.024 & 0.067 & -0.009 & 0.106 & -0.025 & 0.229 & 14.590 & 0.057 & 0.455 & 0.091 & 0.273 & 0.000 \\
\hline Niger & 1965-1997 & -0.024 & 0.068 & -0.002 & 0.165 & 0.008 & 0.168 & 11.646 & 0.041 & 0.278 & 0.000 & 0.242 & 0.121 \\
\hline Nigeria & 1965-1997 & -0.001 & 0.094 & 0.023 & 0.276 & 0.022 & 0.255 & 0.652 & -0.023 & 0.420 & 0.000 & 0.061 & 0.000 \\
\hline Pakistan & 1965-1997 & 0.030 & 0.030 & -0.008 & 0.148 & -0.025 & 0.159 & 3.522 & -0.043 & 0.301 & 0.000 & 0.364 & 0.000 \\
\hline Rwanda & 1965-1997 & 0.001 & 0.121 & -0.007 & 0.202 & 0.023 & 0.267 & 16.449 & 0.030 & 0.358 & 0.000 & 0.091 & 0.030 \\
\hline Senegal & 1965-1997 & -0.004 & 0.053 & -0.005 & 0.161 & -0.011 & 0.085 & 10.979 & 0.012 & 0.264 & 0.000 & 0.212 & 0.000 \\
\hline Sierra Leone & 1965-1996 & -0.010 & 0.069 & -0.023 & 0.144 & -0.010 & 0.123 & 9.039 & 0.035 & 0.368 & 0.000 & 0.063 & 0.000 \\
\hline Tanzania & 1988-1997 & -0.015 & 0.065 & -0.008 & 0.200 & -0.023 & 0.048 & 21.275 & -0.053 & 0.223 & 0.000 & 0.600 & 0.000 \\
\hline Togo & 1965-1997 & -0.004 & 0.092 & -0.016 & 0.129 & -0.019 & 0.289 & 10.351 & 0.009 & 0.283 & 0.000 & 0.091 & 0.061 \\
\hline Uganda & 1982-1997 & 0.019 & 0.032 & -0.033 & 0.268 & -0.006 & 0.223 & 11.909 & 0.069 & 0.257 & 0.063 & 0.188 & 0.000 \\
\hline Zambia & 1965-1997 & -0.016 & 0.044 & -0.026 & 0.196 & -0.034 & 0.253 & 12.597 & 0.067 & 0.499 & 0.000 & 0.121 & 0.030 \\
\hline Zimbabwe & 1965-1997 & 0.020 & 0.080 & -0.011 & 0.076 & -0.019 & 0.094 & 2.715 & 0.095 & 0.796 & 0.000 & 0.152 & 0.030 \\
\hline \multirow[t]{2}{*}{ Income group } & $\begin{array}{l}\text { Number of } \\
\text { countries }\end{array}$ & $\begin{array}{l}\text { Average } \\
\text { growth real } \\
\text { GDP per } \\
\text { capita }\end{array}$ & $\begin{array}{c}\text { Average } \\
\text { standard } \\
\text { deviation of } \\
\text { real GDP per } \\
\text { capita }\end{array}$ & $\begin{array}{l}\text { Average } \\
\text { growth rate of } \\
\text { DM index }\end{array}$ & $\begin{array}{c}\text { Average } \\
\text { standard } \\
\text { deviation of } \\
\text { the growth rate } \\
\text { of the DM } \\
\text { index }\end{array}$ & $\begin{array}{c}\text { Average } \\
\text { growth of } \\
\text { terms of trade }\end{array}$ & $\begin{array}{c}\text { Standard } \\
\text { deviation of } \\
\text { the average } \\
\text { growth of } \\
\text { terms of trade }\end{array}$ & $\begin{array}{c}\text { Average aid as } \\
\text { a fraction of } \\
\text { GNI }\end{array}$ & $\begin{array}{c}\text { Average } \\
\text { growth of real } \\
\text { per capita aid }\end{array}$ & $\begin{array}{c}\text { Standard } \\
\text { deviation of } \\
\text { the growth of } \\
\text { real per capita } \\
\text { aid }\end{array}$ & $\begin{array}{c}\text { Average } \\
\text { number of } \\
\text { large geological } \\
\text { disasters per } \\
\text { year }\end{array}$ & $\begin{array}{c}\text { Average } \\
\text { number of } \\
\text { large climatic } \\
\text { disasters per } \\
\quad \text { year }\end{array}$ & $\begin{array}{c}\text { Average } \\
\text { number of } \\
\text { large } \\
\text { Humanitarian } \\
\text { disasters per } \\
\text { year }\end{array}$ \\
\hline & (1) & (2) & (3) & (4) & (5) & (6) & (7) & (8) & (9) & (10) & (11) & (12) & (13) \\
\hline Low & 40 & 0.002 & 0.069 & -0.010 & 0.171 & -0.010 & 0.164 & 10.945 & 0.036 & 0.354 & 0.009 & 0.234 & 0.031 \\
\hline Middle & 72 & 0.018 & 0.059 & 0.001 & 0.166 & -0.001 & 0.115 & 7.304 & 0.050 & 0.649 & 0.018 & 0.129 & 0.005 \\
\hline High & 30 & 0.029 & 0.031 & -- & -- & -0.001 & 0.041 & 2.665 & 0.034 & 0.718 & 0.006 & 0.038 & 0.001 \\
\hline
\end{tabular}




\section{Table 2: External shocks and Output Volatility}

In Panel A, columns (1) and (2) show the fraction of the variance of the forecast error of (log) real GDP per capita at various horizons that can be attributed to external versus and internal shocks respectively. Columns (3) to (9) show the relative contribution of each different external shocks to the total fraction presented in column (1). The different columns in Panel B show the same decomposition for the variance of the forecast error of (log) real GDI per capita (real GDP adjusted for terms of trade changes).

\begin{tabular}{|c|c|c|c|c|c|c|c|c|c|}
\hline \multirow{3}{*}{$\begin{array}{c}\text { Forecast Horizon } \\
\text { (years) }\end{array}$} & \multicolumn{2}{|c|}{$\begin{array}{c}\text { Fraction of the variance of } \\
\text { the forecast error of } \\
\text { explained by: }\end{array}$} & \multicolumn{7}{|c|}{$\begin{array}{l}\text { Fraction of the variance accounted for all external shocks that can be attributed to shocks } \\
\text { to: }\end{array}$} \\
\hline & $\begin{array}{l}\text { All external } \\
\text { shocks }\end{array}$ & $\begin{array}{l}\text { Non-external } \\
\text { shocks }\end{array}$ & $\begin{array}{l}\text { World } \\
\text { Output }\end{array}$ & $\begin{array}{l}\text { Commodity } \\
\text { Prices }\end{array}$ & $\begin{array}{l}\text { Interest } \\
\text { Rate }\end{array}$ & $\begin{array}{c}\text { Geological } \\
\text { Disasters }\end{array}$ & $\begin{array}{l}\text { Climatic } \\
\text { Disasters }\end{array}$ & $\begin{array}{l}\text { Humanit. } \\
\text { Crises }\end{array}$ & Aid \\
\hline & $(1)$ & (2) & (3) & (4) & (5) & (6) & $(7)$ & (8) & (9) \\
\hline \multicolumn{10}{|l|}{ A. Real GDP } \\
\hline 1 & 2 & 98 & 15.7 & 6.8 & 16.2 & 0.5 & 33.0 & 0.0 & 27.9 \\
\hline 5 & 9 & 91 & 12.1 & 27.8 & 3.4 & 0.1 & 17.1 & 13.3 & 26.3 \\
\hline 10 & 11 & 89 & 10.1 & 36.5 & 3.0 & 0.1 & 13.9 & 11.6 & 24.9 \\
\hline B. Real GDI & (1) & (2) & (3) & (4) & (5) & (6) & (7) & (8) & (9) \\
\hline 1 & 6 & 94 & 0.1 & 52.8 & 2.2 & 1.5 & 16.5 & 0.3 & 26.5 \\
\hline 5 & 14 & 86 & 10.4 & 61.8 & 2.8 & 1.1 & 13.1 & 3.4 & 7.4 \\
\hline 10 & 16 & 84 & 9.4 & 64.3 & 5 & 1 & 11.1 & 3 & 6.3 \\
\hline
\end{tabular}




\section{Table 3: Robustness}

The table shows the variance decomposition of the forecast error of real per capita GDP at 1, 5, and 10 year ahead for different specifications. Panel (1) shows the results obtained using the benchmark specification but allowing only one lag. Panels (2) and (3) reports the results obtained using a different ordering for the exogenous block that puts the DM terms of trade index first (last), followed (preceded) by the GDP of rich countries and the international interest rate. The specification reported in Panel (4) assumes that only the common component of the DM terms of trade affects the international variable, while in panel (5) we assume that there is no feedbak from the DM terms of trade index to the international variables. The results on Panel (6) and (7) use the benchmark specification but only data from the period after 1973 and excluding oild producer countries respectively. Panel (8) reports the results obtained when aid flows are not included in the system. The results in Panel (9) correspond to those obtained under the benchmark specification but using the broad terms of trade index instead of the DM commodity based terms of trade index. Panels (10) and (11) report results obtained using the benchmark identification assumptions but estimating the model in first differences instead of levels and using the DM index and the broad terms of trade measures respectively.

\begin{tabular}{|c|c|c|c|c|c|c|c|c|c|c|c|}
\hline & & \multirow{2}{*}{$\begin{array}{l}\text { Forecast } \\
\text { Horizon } \\
\text { (years) }\end{array}$} & \multicolumn{2}{|c|}{$\begin{array}{c}\text { Fraction of the variance } \\
\text { of the forecast error of } \\
\text { output variance } \\
\text { explained by: }\end{array}$} & \multicolumn{7}{|c|}{$\begin{array}{l}\text { Fraction of the variance of output accounted for external shocks that can be attributed to } \\
\text { shocks to: }\end{array}$} \\
\hline & & & $\begin{array}{l}\text { All external } \\
\text { shocks }\end{array}$ & $\begin{array}{l}\text { Non- } \\
\text { external } \\
\text { shocks } \\
\end{array}$ & $\begin{array}{l}\text { World } \\
\text { Output }\end{array}$ & $\begin{array}{l}\text { Commodity } \\
\text { Prices }\end{array}$ & $\begin{array}{l}\text { Interest } \\
\text { Rate }\end{array}$ & $\begin{array}{l}\text { Geological } \\
\text { Disasters }\end{array}$ & $\begin{array}{l}\text { Climatic } \\
\text { Disasters }\end{array}$ & $\begin{array}{l}\text { Human } \\
\text { Disasters }\end{array}$ & Aid \\
\hline \multirow{3}{*}{ One lag } & \multirow{3}{*}{ (1) } & 1 & 1 & 99 & 43.6 & 1.1 & 5.8 & 0.5 & 16.8 & 2.6 & 29.6 \\
\hline & & 5 & 2 & 98 & 31.7 & 37.7 & 6.6 & 0.1 & 14.5 & 3 & 6.4 \\
\hline & & 10 & 4 & 97 & 20.1 & 43.8 & 17.7 & 0.1 & 9.3 & 2.2 & 6.7 \\
\hline \multirow{3}{*}{$\begin{array}{l}\text { Alternate ordering } \\
\text { I }\end{array}$} & \multirow{3}{*}{ (2) } & 1 & 2 & 98 & 13.8 & 8.7 & 16.2 & 0.5 & 33 & 0 & 27.9 \\
\hline & & 5 & 9 & 91 & 9.6 & 30.2 & 3.4 & 0.1 & 17.1 & 13.3 & 26.3 \\
\hline & & 10 & 11 & 89 & 8 & 38.6 & 3 & 0.1 & 13.9 & 11.6 & 24.9 \\
\hline \multirow{3}{*}{$\begin{array}{l}\text { Alternate ordering } \\
\text { II }\end{array}$} & \multirow{3}{*}{ (3) } & 1 & 2 & 98 & 15.7 & 8.1 & 15 & 0.5 & 33 & 0 & 27.9 \\
\hline & & 5 & 9 & 91 & 12.1 & 27.8 & 3.4 & 0.1 & 17.1 & 13.3 & 26.3 \\
\hline & & 10 & 11 & 89 & 10.1 & 36.6 & 2.8 & 0.1 & 13.9 & 11.6 & 24.9 \\
\hline \multirow{3}{*}{$\begin{array}{c}\text { Average DMTT } \\
\text { affects GDPH and } \\
\text { R }\end{array}$} & \multirow{3}{*}{ (4) } & 1 & 2 & 98 & 16.1 & 7.1 & 13.9 & 0.5 & 33.8 & 0 & 28.6 \\
\hline & & 5 & 10 & 90 & 10.6 & 35 & 2.5 & 0.1 & 15.6 & 12.1 & 24 \\
\hline & & 10 & 12 & 88 & 9.1 & 42.9 & 2.1 & 0.1 & 12.6 & 10.6 & 22.6 \\
\hline \multirow{3}{*}{$\begin{array}{l}\text { DMTT does not } \\
\text { affect GDPH nor } \\
\text { R }\end{array}$} & \multirow{3}{*}{ (5) } & 1 & 2 & 98 & 15.7 & 8 & 16 & 0.5 & 32.5 & 0 & 27.5 \\
\hline & & 5 & 9 & 91 & 12.8 & 25.5 & 3.7 & 0.1 & 17.5 & 13.6 & 26.9 \\
\hline & & 10 & 11 & 89 & 10.6 & 34.6 & 3.2 & 0.1 & 14.2 & 11.9 & 25.5 \\
\hline \multirow{3}{*}{$\begin{array}{l}\text { Aid not included in } \\
\text { the system }\end{array}$} & \multirow{3}{*}{ (6) } & 1 & 2 & 98 & 23.7 & 4.3 & 25.4 & 1.6 & 45 & 0 & -- \\
\hline & & 5 & 7 & 93 & 17.2 & 30.9 & 6.4 & 0.4 & 25.1 & 19.9 & -- \\
\hline & & 10 & 8 & 92 & 14.4 & 41 & 5.7 & 0.3 & 20.3 & 18.2 & -- \\
\hline \multirow{3}{*}{ Post 1973 sample } & \multirow{3}{*}{ (7) } & 1 & 2 & 98 & 11.8 & 5.8 & 33.2 & 0 & 33.6 & 0.4 & 15.1 \\
\hline & & 5 & 9 & 91 & 6.5 & 8 & 5.5 & 1 & 12.6 & 7.6 & 58.7 \\
\hline & & 10 & 11 & 89 & 14.5 & 7.2 & 5.8 & 0.9 & 10.2 & 6.1 & 55.2 \\
\hline \multirow{3}{*}{$\begin{array}{l}\text { No oil producers } \\
\text { sample }\end{array}$} & \multirow{3}{*}{ (8) } & 1 & 2 & 98 & 11.8 & 0.5 & 16.5 & 1.1 & 34.2 & 0 & 36 \\
\hline & & 5 & 9 & 92 & 7.3 & 27.6 & 3.8 & 0.8 & 21.6 & 16.3 & 22.7 \\
\hline & & 10 & 9 & 91 & 6.8 & 33.5 & 3.4 & 0.8 & 19 & 15.8 & 20.7 \\
\hline \multirow{3}{*}{$\begin{array}{l}\text { Using broad terms } \\
\text { of trade measure }\end{array}$} & \multirow{3}{*}{$(9)$} & 1 & 3 & 97 & 11.9 & 12.5 & 24.9 & 0.4 & 25.2 & 0 & 25.1 \\
\hline & & 5 & 7 & 93 & 17.4 & 8.8 & 12.5 & 0.4 & 18.9 & 21.4 & 20.6 \\
\hline & & 10 & 8 & 93 & 16.5 & 11.3 & 14.7 & 0.4 & 17 & 21.5 & 18.7 \\
\hline \multirow{3}{*}{$\begin{array}{l}\text { Model estimated in } \\
\text { first differences }\end{array}$} & \multirow{3}{*}{ (10) } & 1 & 3 & 97 & 18.7 & 5.9 & 18.5 & 3 & 18 & 0.3 & 35.5 \\
\hline & & 5 & 7 & 93 & 22.4 & 11.1 & 13.2 & 1.9 & 19.8 & 4.2 & 27.4 \\
\hline & & 10 & 7 & 93 & 23 & 11.3 & 13.2 & 1.9 & 19.5 & 4.1 & 26.9 \\
\hline \multirow{3}{*}{$\begin{array}{l}\text { Model in first } \\
\text { differences using } \\
\text { broad terms of } \\
\text { trade. }\end{array}$} & \multirow{3}{*}{ (11) } & 1 & 4 & 96 & 17.3 & 12.4 & 18.5 & 1.7 & 16.1 & 0.3 & 33.7 \\
\hline & & 5 & 7 & 93 & 21.2 & 14.6 & 14 & 1.3 & 18.1 & 3.8 & 26.9 \\
\hline & & 10 & 8 & 93 & 21.6 & 14.8 & 14 & 1.3 & 18 & 3.7 & 26.6 \\
\hline
\end{tabular}


Table 4: Aid-volatility variance decomposition

In Panel A, columns (1) and (2) show the fraction of the variance of the forecast error of (log) real per capita aid at various horizons that can be attributed to its own shock and all the rest of the shocks included in the system. Columns (3) to (9) show the relative contribution of each different shocks to the total fraction presented in column (1).

\begin{tabular}{|c|c|c|c|c|c|c|c|c|c|}
\hline \multirow{2}{*}{$\begin{array}{c}\text { Forecast Horizon } \\
\text { (years) }\end{array}$} & \multicolumn{2}{|c|}{ Fraction of the variance of } & \multicolumn{7}{|c|}{ Fraction of the variance accounted for non-aid shocks that can be attributed to shocks to: } \\
\hline & $\begin{array}{c}\text { All other } \\
\text { shocks } \\
(1) \\
\end{array}$ & $\begin{array}{c}\text { Aid shocks } \\
\text { (2) }\end{array}$ & $\begin{array}{c}\text { World } \\
\text { Output } \\
(3) \\
\end{array}$ & $\begin{array}{c}\text { Commodity } \\
\text { Prices } \\
(4) \\
\end{array}$ & $\begin{array}{c}\text { Interest } \\
\text { Rate } \\
(5) \\
\end{array}$ & $\begin{array}{c}\text { Geological } \\
\text { Disasters } \\
(6) \\
\end{array}$ & $\begin{array}{c}\text { Climatic } \\
\text { Disasters } \\
(7)\end{array}$ & $\begin{array}{c}\text { Humanit. } \\
\text { Crises } \\
(8)\end{array}$ & $\begin{array}{l}\text { Output } \\
(9) \\
\end{array}$ \\
\hline 1 & 1 & 99 & 28.6 & 11.9 & 9.6 & 44 & 3.2 & 2.6 & 0 \\
\hline 5 & 7 & 93 & 29.8 & 24.5 & 24.2 & 7.8 & 2.2 & 6 & 5.4 \\
\hline 10 & 11 & 89 & 19.6 & 16.6 & 49.5 & 4.7 & 1.4 & 4.3 & 3.9 \\
\hline
\end{tabular}


Table A1: Unit root tests

Panel A reports the results of the Levin-Lin-Chu (2002) panel unit root tests for the panel variables used in the paper. In this panel, column (1) reports the coefficient obtained for the regression of orthogonalized residuals; columns (2) and (3) report the standard and modified tstatistic associated with this coefficient. Column (4) reports the P-value for the null hypothesis that the series follows a unit root process. Column (5) reports the number of observations. The small number of observations compared with those in the paper results from the need to use a balanced panel to perform the test. Results are similar if countries that constraint the time series dimension are dropped from the sample. Column (5) indicates the maximum lag order used in the test. The test included country specific trends and constants. For the variables that are common to all countries, Panel B reports the results of standard Augmented Dickey-Fuller unit root tests. The first column shows the ADF statistic; column (2) presents the corresponding p-value,; column (3) shows the number of observations, and column (4) indicates the number of lagged differences included in the test.. A constant and a trend were included in all ADF tests.

\begin{tabular}{lcccccc}
\hline \hline A. Panel variables: Statistics for Levin-Lin-Chu unit root test & & & & \\
Variable & $\begin{array}{c}\text { Coefficient } \\
\text { (1) }\end{array}$ & $\begin{array}{c}\text { t-value } \\
\text { t-star }\end{array}$ & $\begin{array}{c}\text { P-value } \\
(3)\end{array}$ & $\begin{array}{c}\text { Obs } \\
(5)\end{array}$ & $\begin{array}{c}\text { Lag trunc. } \\
(6)\end{array}$ \\
\hline log real GDP per capita & -0.689 & -13.361 & -7.599 & 0.000 & 320 & 6 \\
log real DM index & -0.898 & -17.553 & -10.911 & 0.000 & 320 & 6 \\
log terms of trade & -0.720 & -16.117 & -9.457 & 0.000 & 320 & 6 \\
\hline
\end{tabular}

B. Common variables: Statistics for Augmented Dickey-Fuller unit root test

\begin{tabular}{lcccc} 
Variable & $\begin{array}{c}\mathrm{Z}(\mathrm{t}) \\
(1)\end{array}$ & $\begin{array}{c}\text { P-value } \\
(2)\end{array}$ & $\begin{array}{c}\text { Obs } \\
(3)\end{array}$ & $\begin{array}{c}\text { Lags } \\
(4)\end{array}$ \\
\hline log GDP per capita rich countries & -2.951 & 0.146 & 31 & 1 \\
$\log$ real interest rate & -2.560 & 0.299 & 31 & 1 \\
\hline \hline
\end{tabular}


Figure 1: Rich-countries' GDP, average DM index, terms of trade, and real interest rate

Rich countries' GDP is the GDP per capita of high income OECD countries expressed in 1995 US\$. The DM index is the Deaton-Miller commodity based terms of trade index, terms of trade is the ratio of exports to import prices from Penn World Tables 6.1. The international real interest rate corresponds to the nominal six month LIBOR offer rate in US dollars deflated by the change in the US Producer's Price Index. All growth rates correspond to the change in the log of the different variables. The three series have been demeaned and standardized to highlight their co-movement.

\section{Panel A}

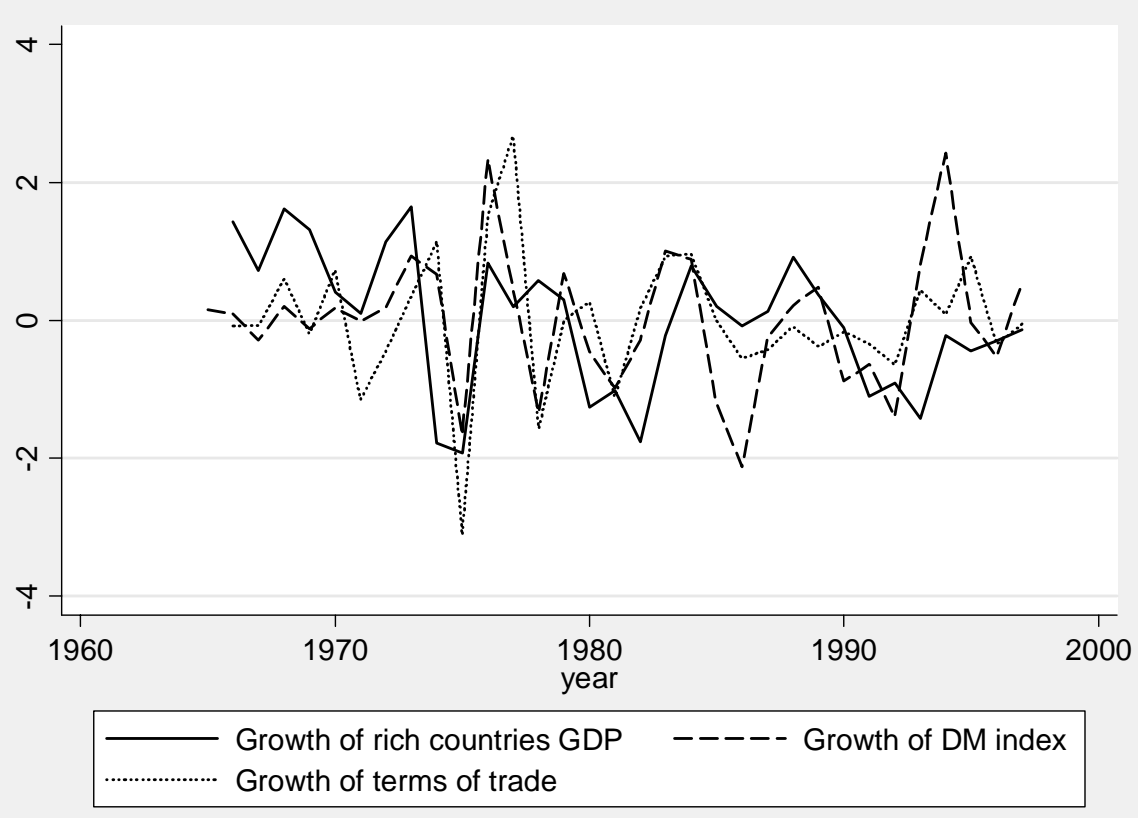

\section{Panel B}

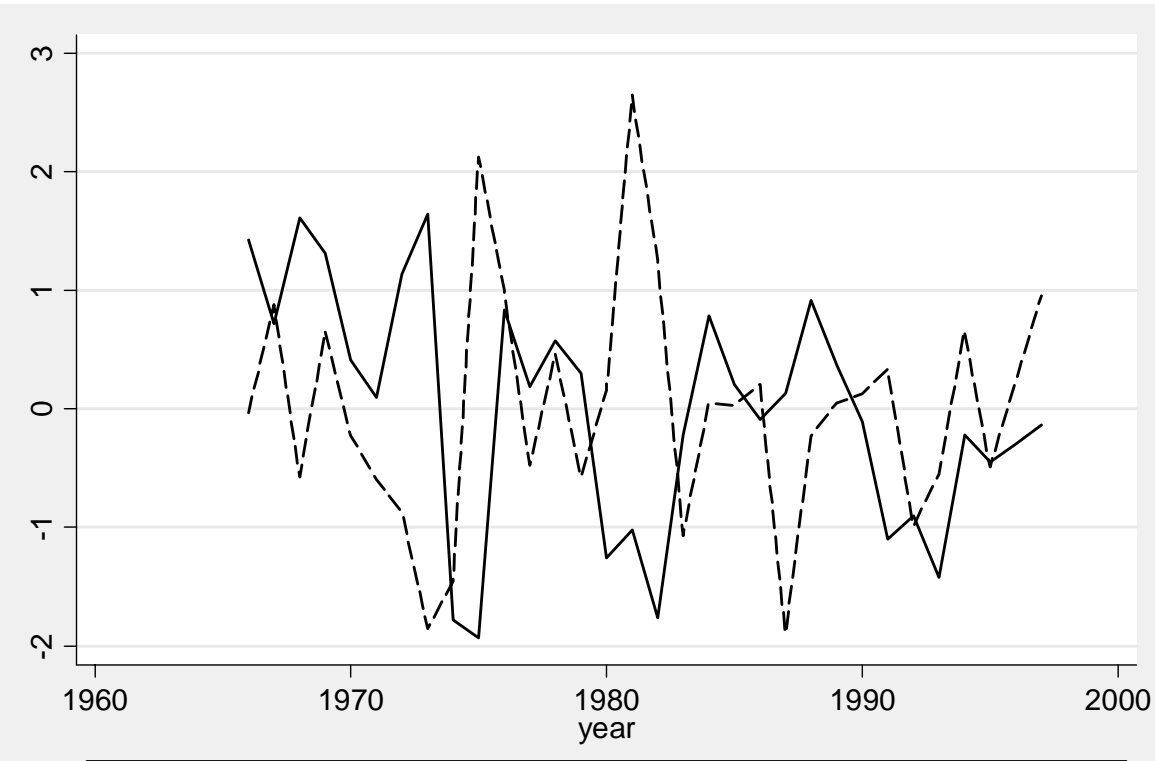

Growth of rich countries GDP - - - Growth of int. real interest rate 


\section{Figure 2: External shocks and real activity}

The different panels of the figure exhibit the impulse-response functions of log real GDP per capita to different external shocks. Panel A shows the IRF to a one standard deviation shock to the log real GDP per capita of high income OECD countries. Panel B shows the IRF of log GDP to a one standard deviation shock to the process followed by the $\log$ Deaton Miller commodity based terms of trade index (DM index). Panel C presents the IRF to a one standard deviation to the $\log$ six month nominal LIBOR rate. Panels D to F show the IRF to a Geological, Climatic, and Humanitarian disasters respectively. Panel G presents the IRF to a one standard deviation shock to per-capita aid flows. Panel H shows the IRF of output to its own innovation. The time horizon is in years. Each panel plots the estimated IRF (dark lines) and the corresponding empirical 80 percent confidence interval (broken lines) computed by non-parameteric bootstrapping.

\section{A. Shock to rich countries GDP}

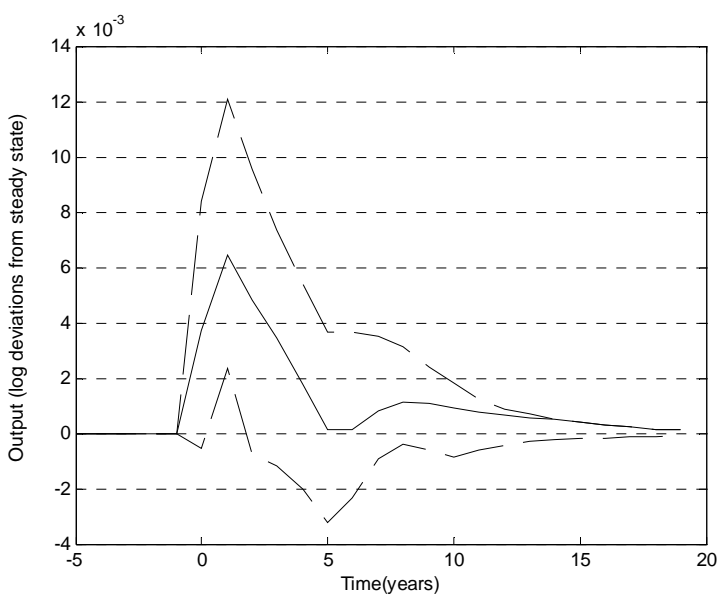

C. Shock to international interest rates

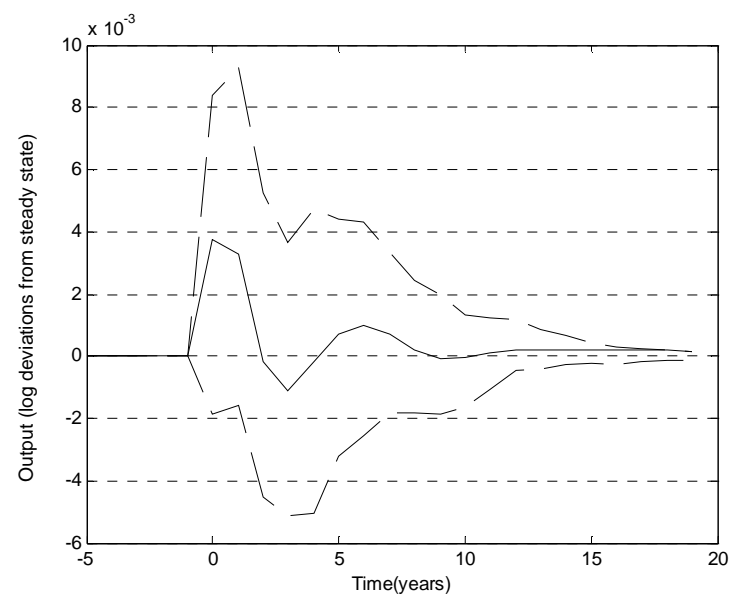

\section{B. Shock to DM commodity prices index}

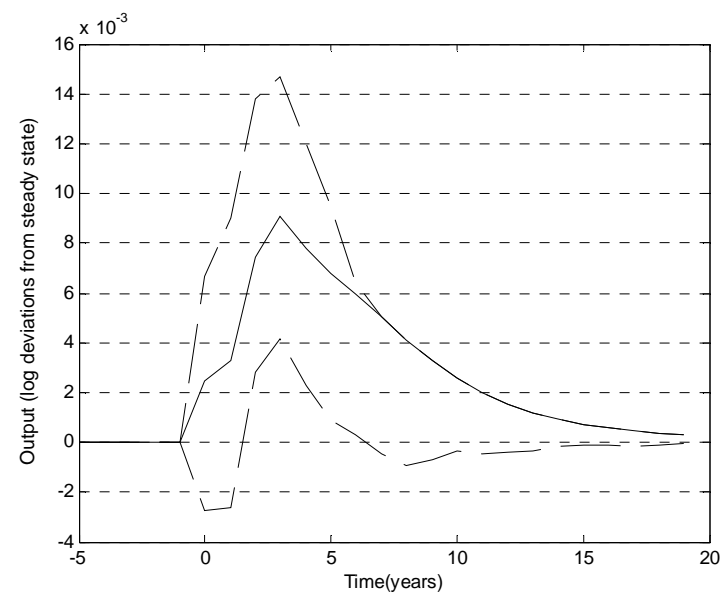

\section{Geological Disaster}

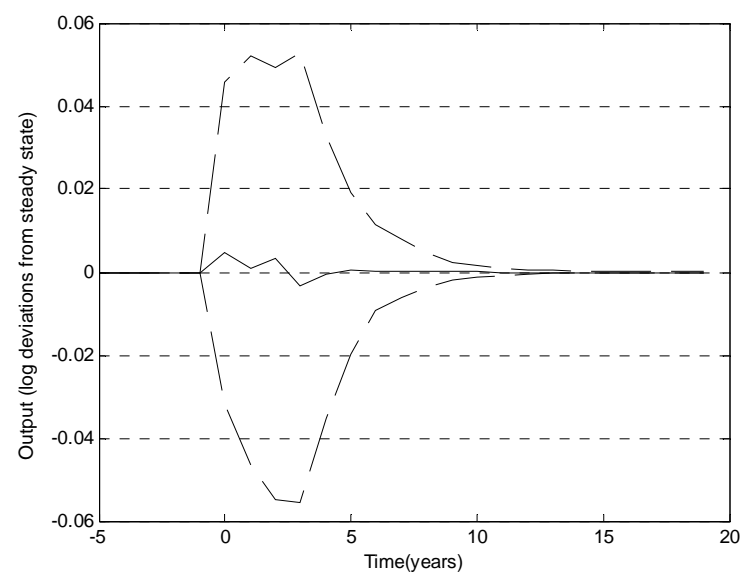

\section{Continues next page}


Figure 2 continued

\section{E. Climatic Disaster}

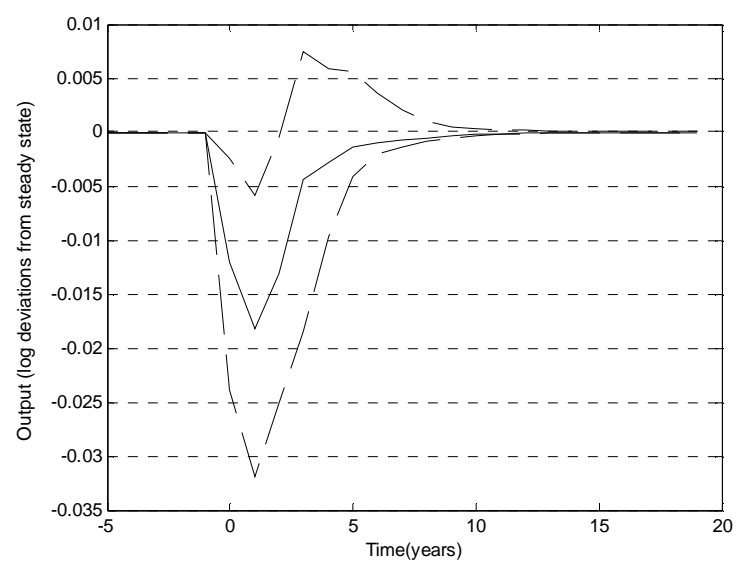

\section{G. Shock to per capita aid flows}

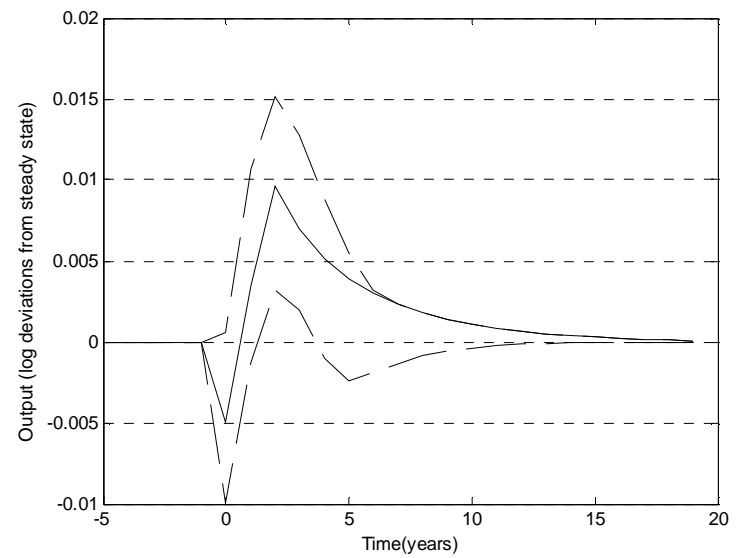

F. Human Disaster

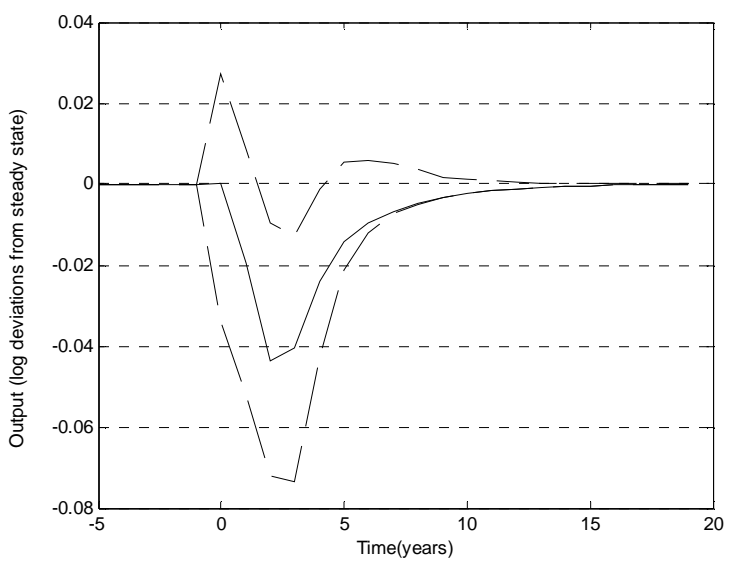

\section{H. Shock to real per capita GDP}

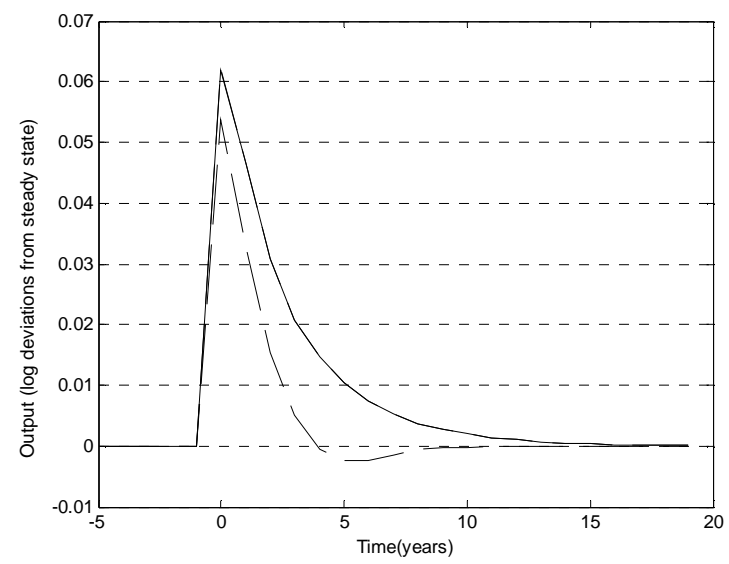




\section{Figure 3: External shocks and Gross Domestic Income}

The different panels of the figure exhibit the impulse-response functions of log real GDI per capita to different external shocks. Panel A shows the IRF to a one standard deviation shock to the log real GDP per capita of high income OECD countries. Panel B shows the IRF of log GDP to a one standard deviation shock to the process followed by the $\log$ Deaton Miller commodity based terms of trade index (DM index). Panel C presents the IRF to a one standard deviation to the $\log$ six month nominal LIBOR rate. Panels D to F show the IRF to a Geological, Climatic, and Humanitarian disasters respectively. Panel G presents the IRF to a one standard deviation shock to per-capita aid flows. The time horizon is in years. Each panel plots the estimated IRF (dark lines) and the corresponding empirical 80 percent confidence interval (broken lines) computed by non-parameteric bootstrapping.

\section{A. Shock to rich countries GDP}

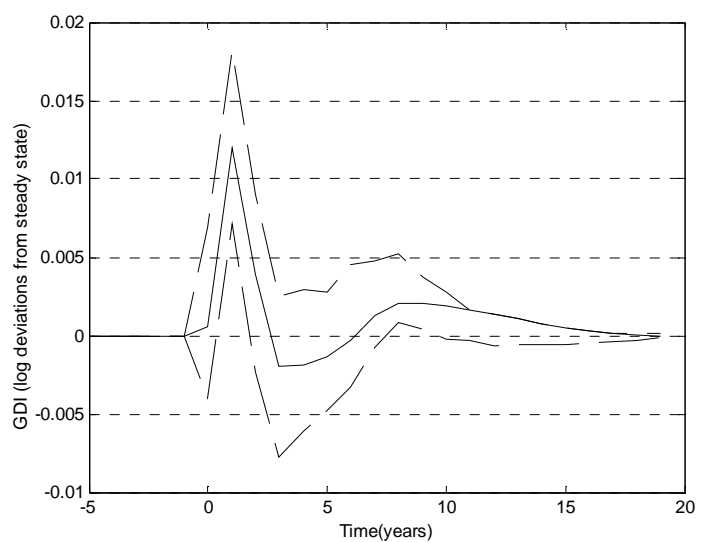

C. Shock to international interest rates

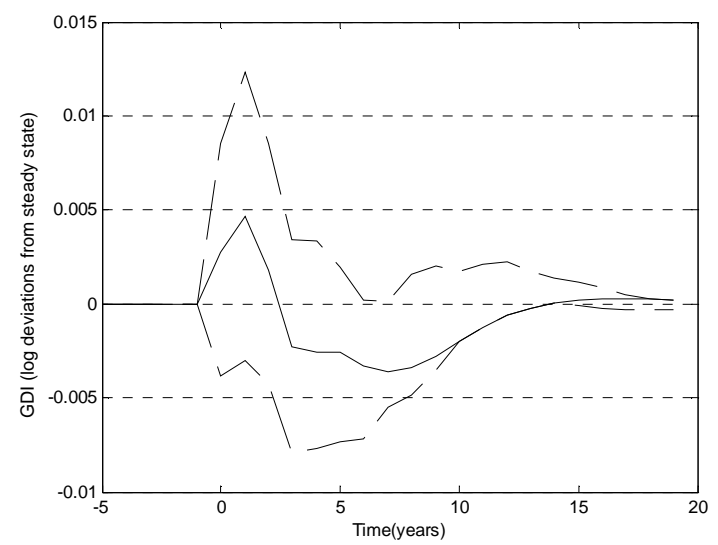

\section{B. Shock to DM commodity prices index}

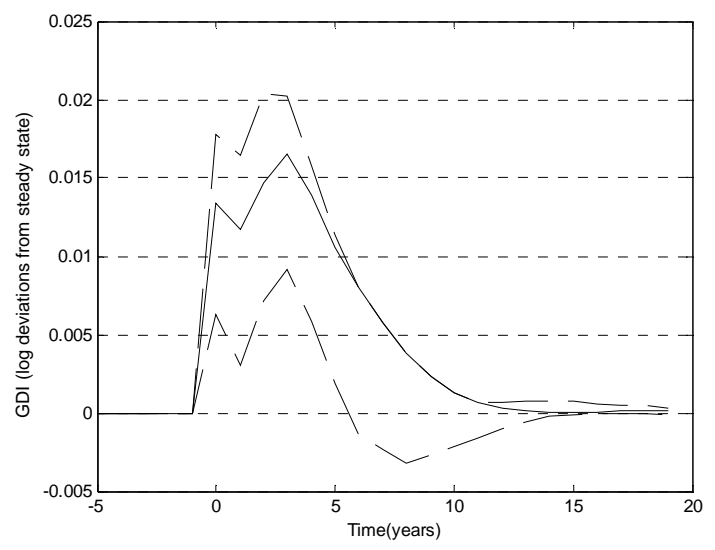

D. Geological Disaster

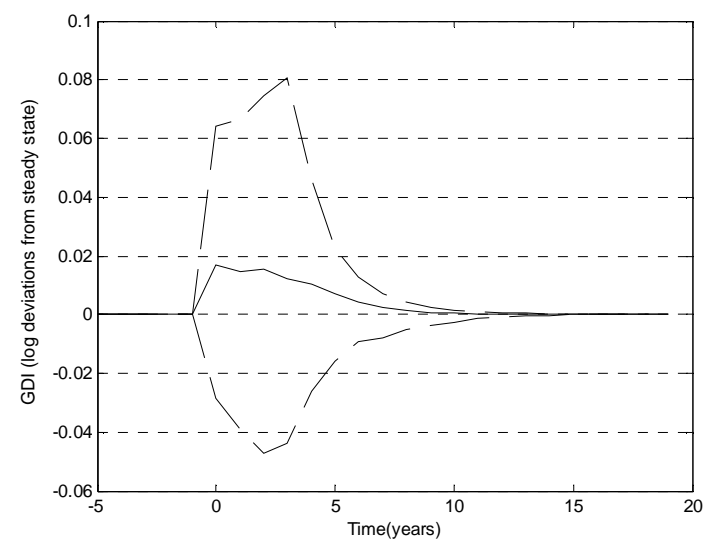

Continues next page 
Figure 3 continued

\section{E. Climatic Disaster}

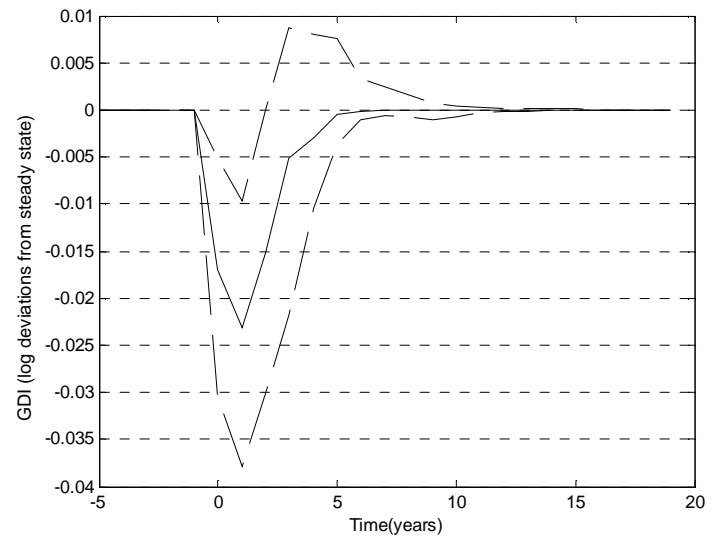

G. Shock to per capita aid flows

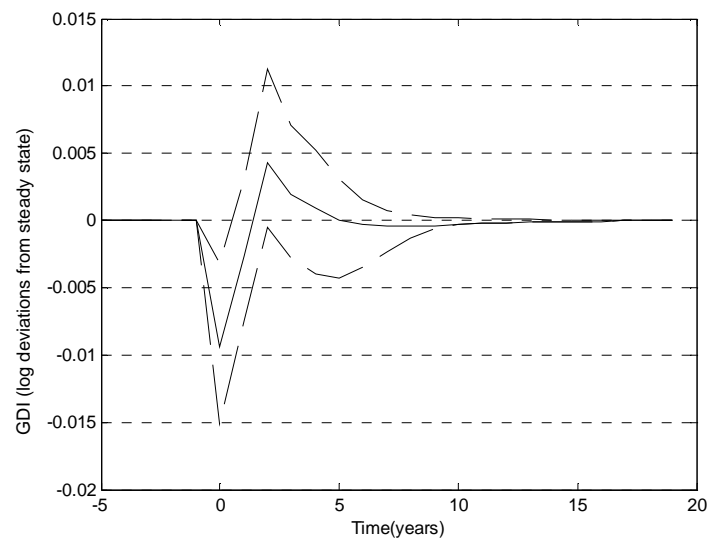

\section{F. Human Disaster}

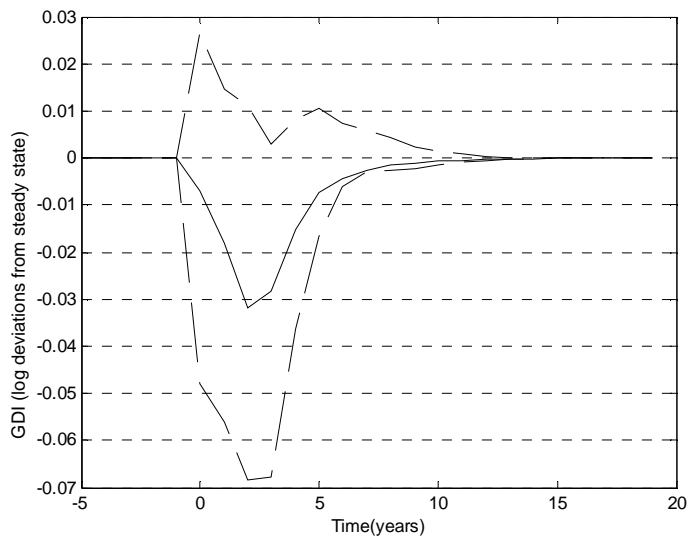




\section{Figure 4: External shocks, Government Expenditure and the Current Account}

The different panels of the figure exhibit the impulse-response functions of log real GDI per capita, Government expenditure, and Net Exports to different external shocks. Panel A shows the IRF to a one standard deviation shock to the log real GDP per capita of high income OECD countries. Panel B shows the IRF of $\log$ GDP to a one standard deviation shock to the process followed by the log Deaton Miller commodity based terms of trade index (DM index). Panel $\mathrm{C}$ presents the IRF to a one standard deviation to the log six month nominal LIBOR rate. Panels D to F show the IRF to a Geological, Climatic, and Humanitarian disasters respectively. Panel G presents the IRF to a one standard deviation shock to per-capita aid flows. The time horizon is in years.

\section{A. Shock to rich countries GDP}

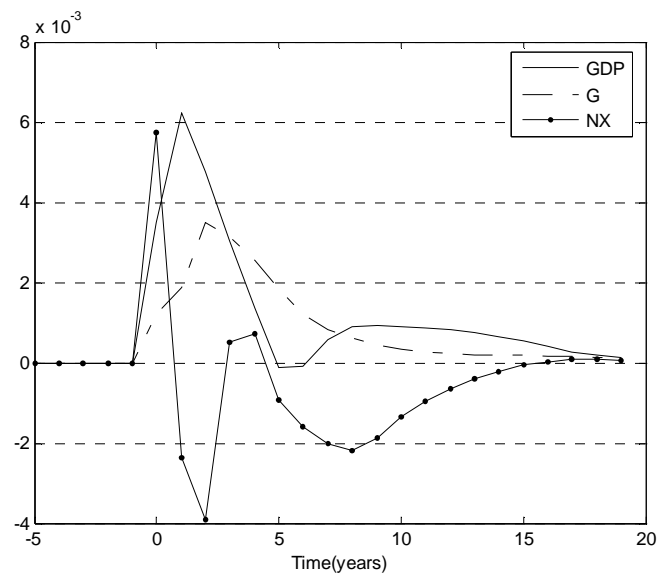

C. Shock to international interest rates

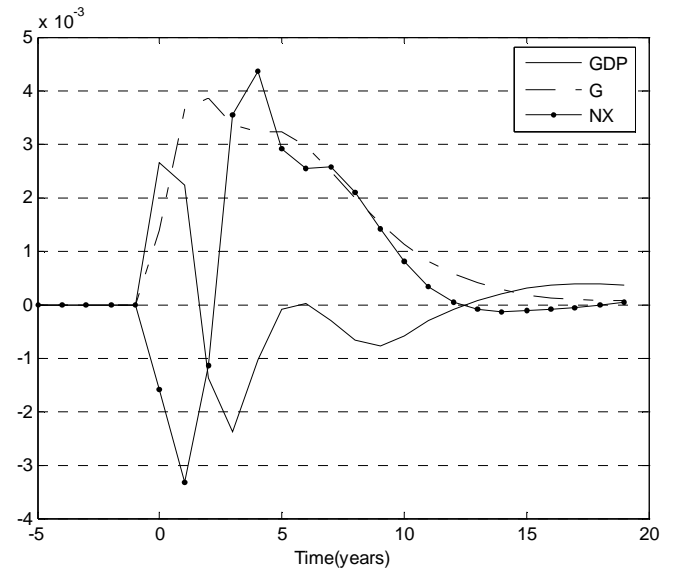

\section{B. Shock to DM commodity prices index}

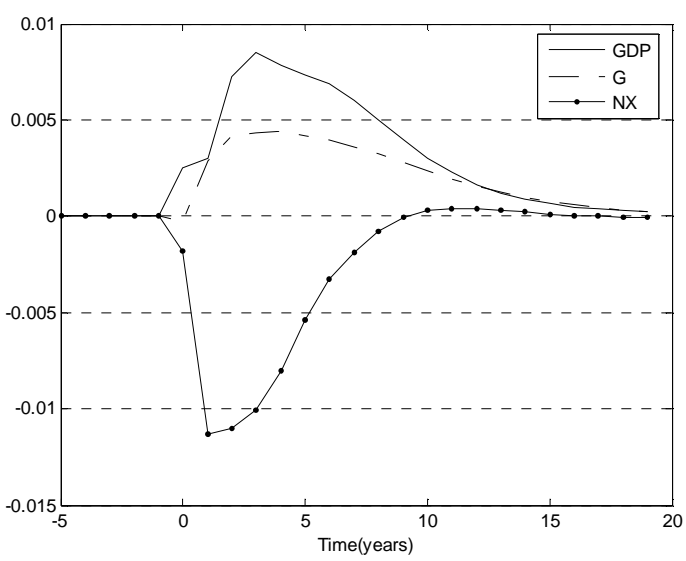

D. Geological Disaster

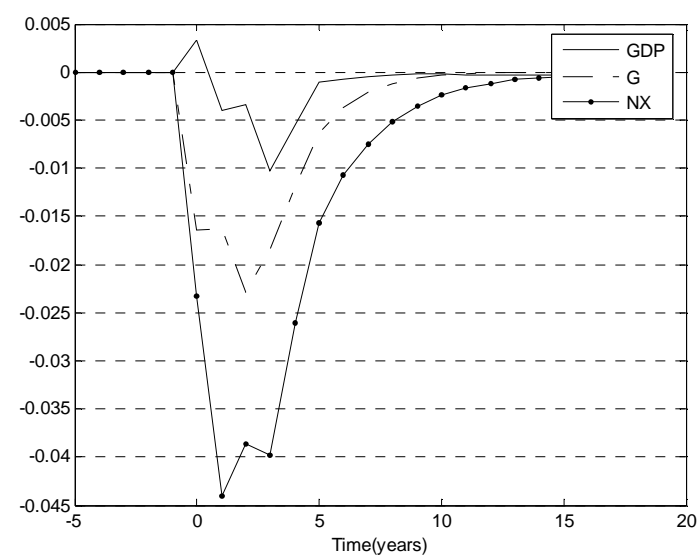

Continues next page 
Figure 4 continued

\section{E. Climatic Disaster}

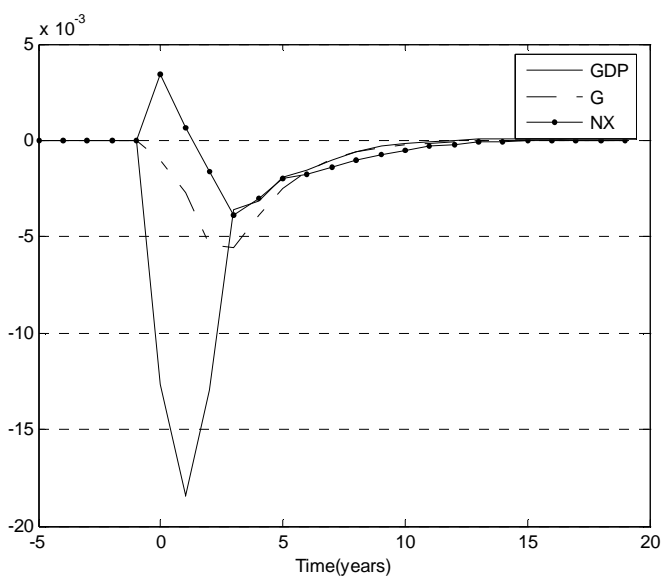

G. Shock to per capita aid flows

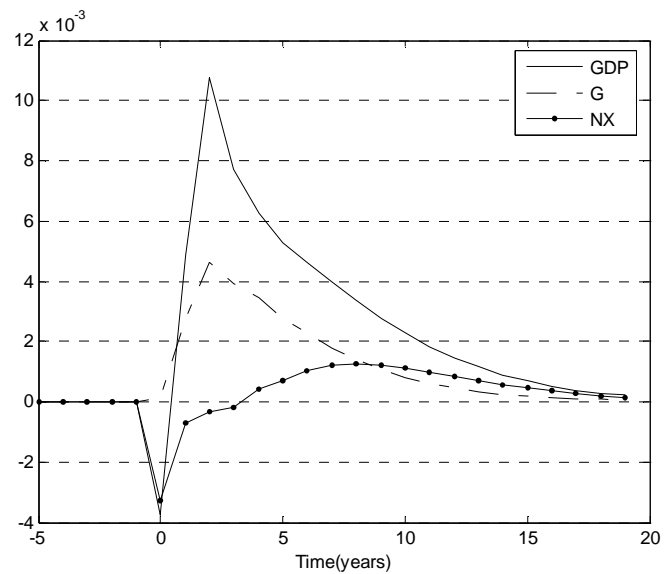

\section{F. Human Disaster}

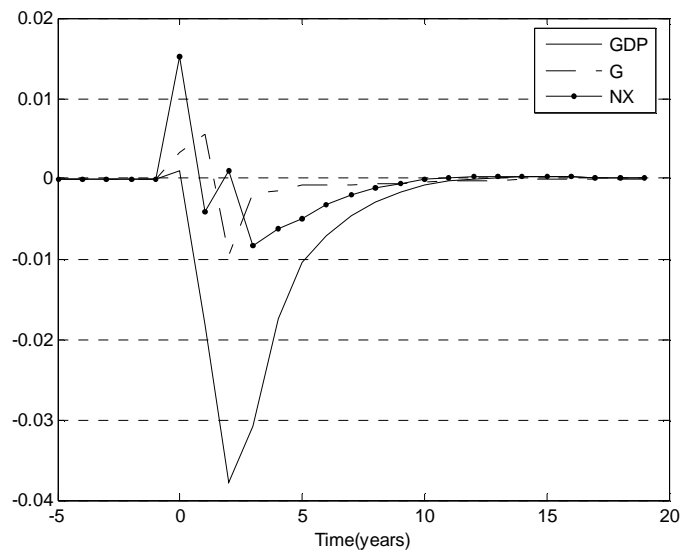




\section{Figure 5: The determinants of Aid}

The different panels of the figure exhibit the impulse-response functions of log real per capita Aid flows to different external shocks. Panel A shows the IRF to a one standard deviation shock to the log real GDP per capita of high income OECD countries. Panel B shows the IRF of log GDP to a one standard deviation shock to the process followed by the log Deaton Miller commodity based terms of trade index (DM index). Panel C presents the IRF to a one standard deviation to the log six month nominal LIBOR rate. Panels D to F show the IRF to a Geological, Climatic, and Humanitarian disasters respectively. Panel G presents the IRF to a one standard deviation shock to real per-capita GDP. The time horizon is in years.

\section{A. Shock to rich countries GDP}

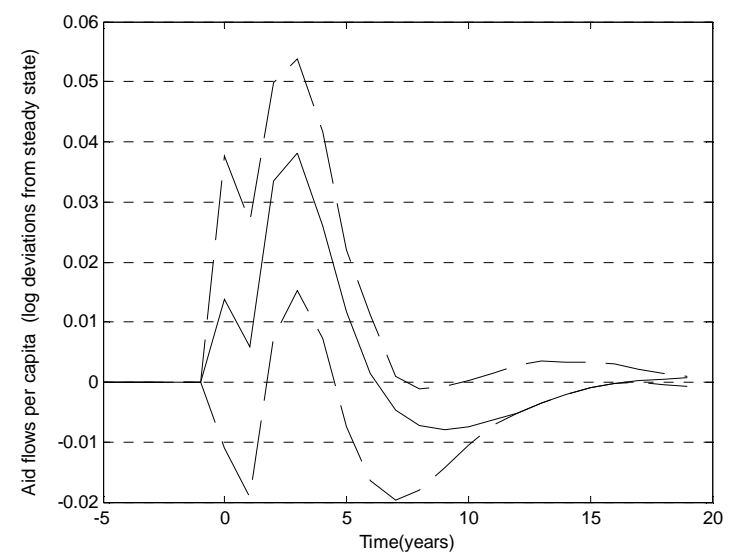

C. Shock to international interest rates

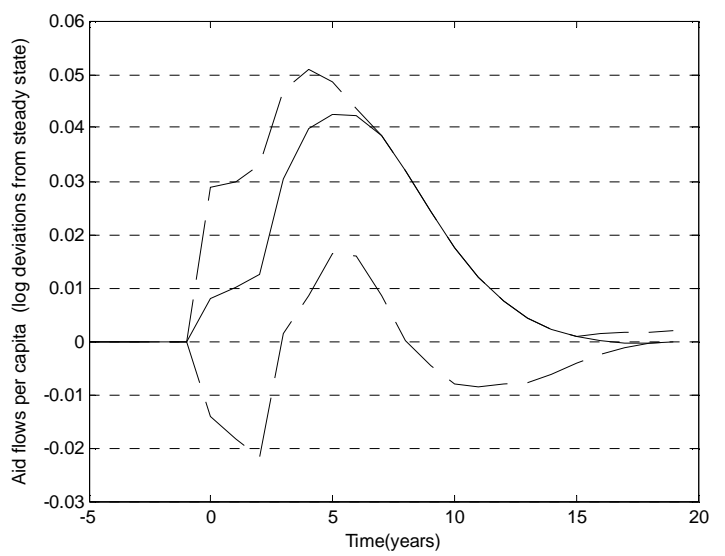

\section{B. Shock to DM commodity prices index}

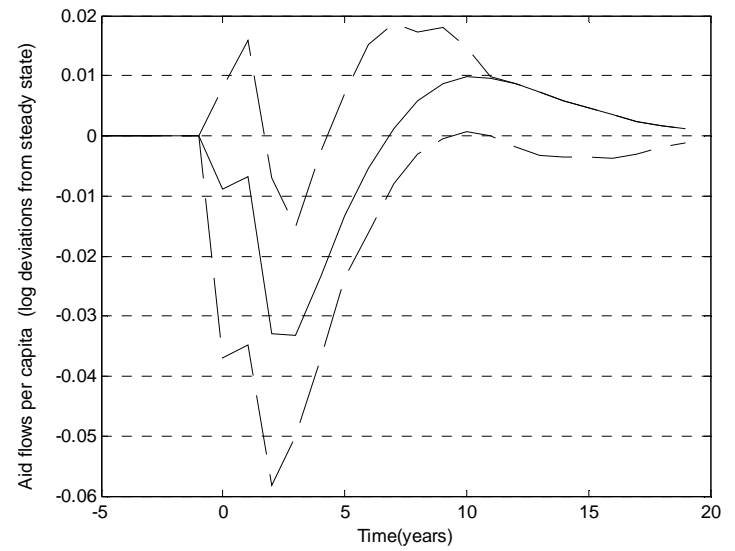

D. Geological Disaster

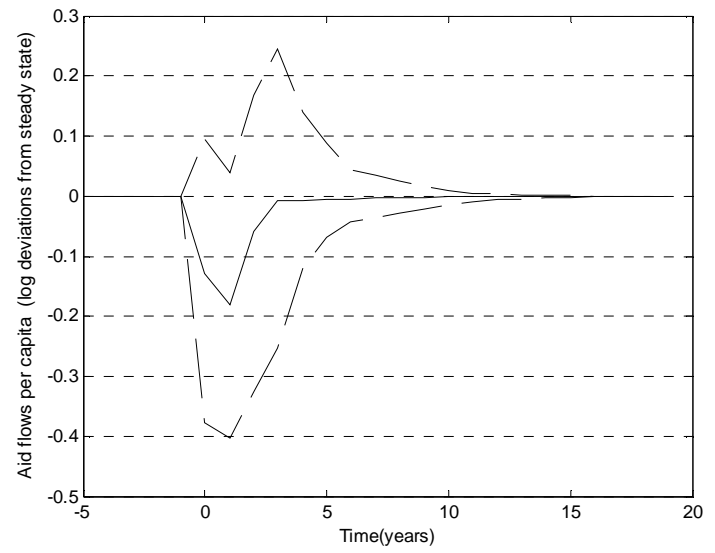

Continues next page 
Figure 5 continued

E. Climatic Disaster

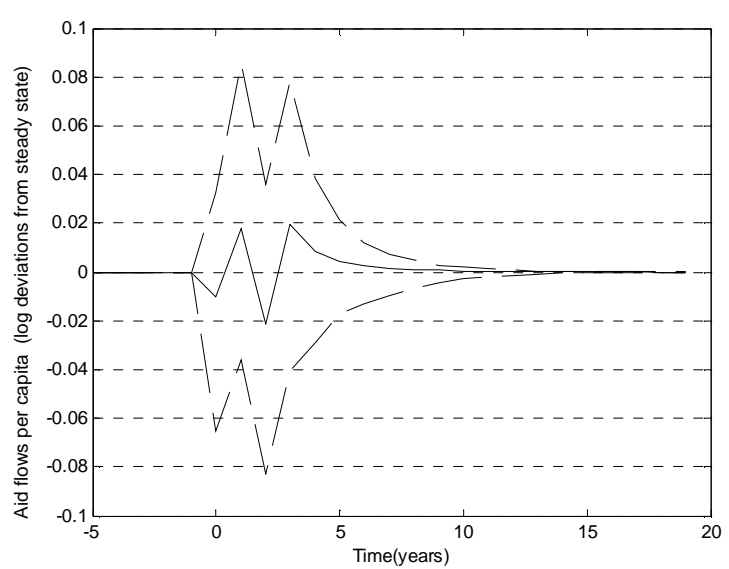

G. Shock to real per capita GDP

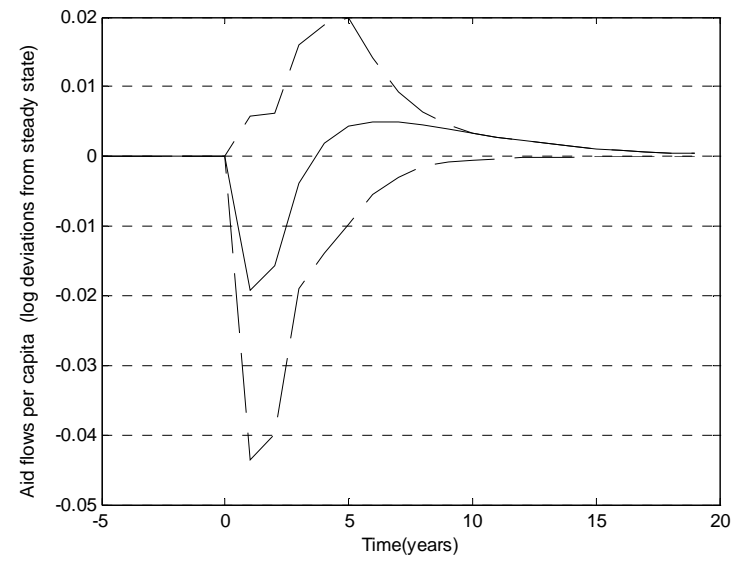

\section{F. Human Disaster}

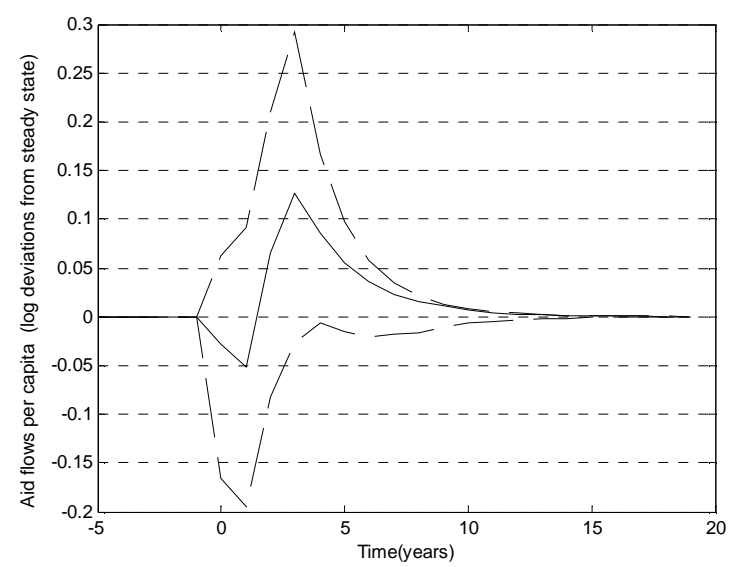




\section{Figure 6: External shocks in open and closed economies}

The different panels of the figure exhibit the impulse-response functions of log real per capita GDP to different external shocks in both open and closed economies. Panel A shows the IRF to a one standard deviation shock to the log real GDP per capita of high income OECD countries. Panel B shows the IRF of $\log$ GDP to a one standard deviation shock to the process followed by the log Deaton Miller commodity based terms of trade index (DM index). Panel C presents the IRF to a one standard deviation to the log six month nominal LIBOR rate. Panels D to F show the IRF to a Geological, Climatic, and Humanitarian disasters respectively. Panel G presents the IRF to a one standard deviation shock to real per-capita aid flows. The time horizon is in years.

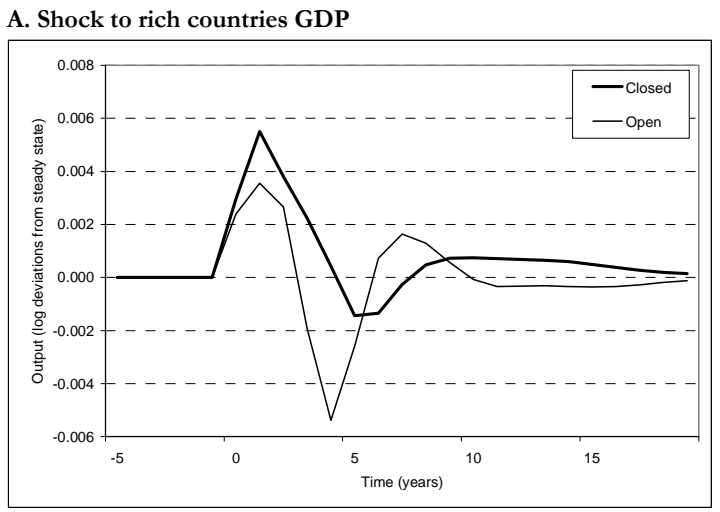

B. Shock to DM commodity prices index

\section{Shock to international interest rates}
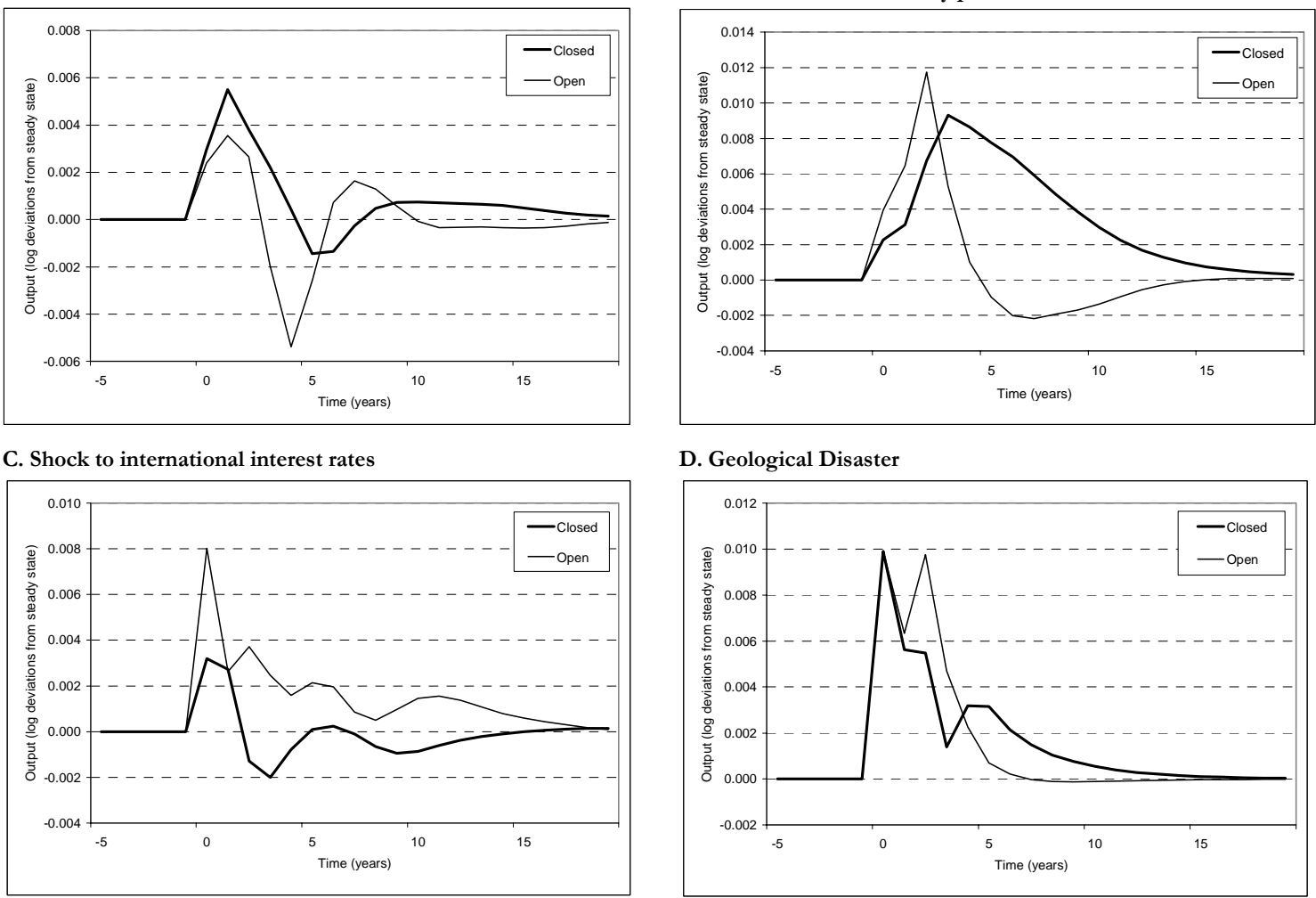

\section{Geological Disaster}

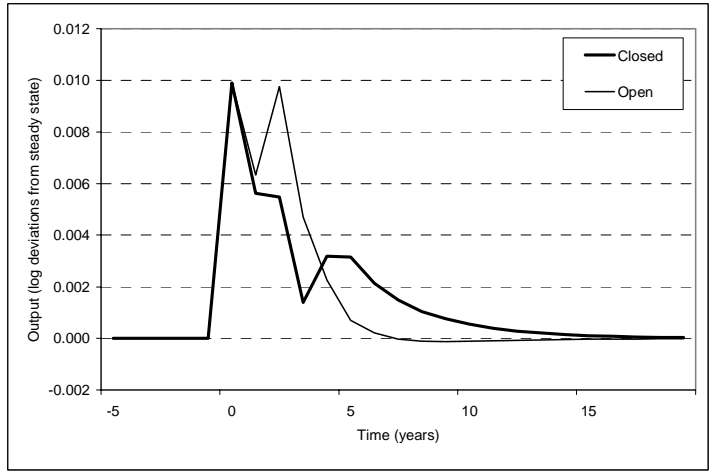

Continues next page 
Figure 6 continued

E. Climatic Disaster

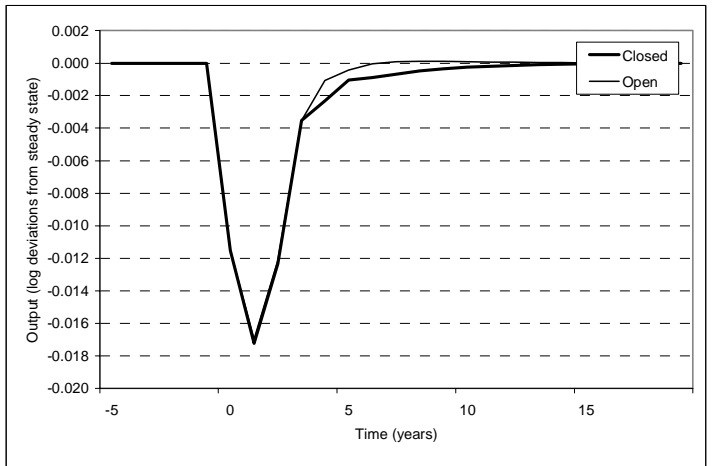

G. Shock to real per capita aid flows

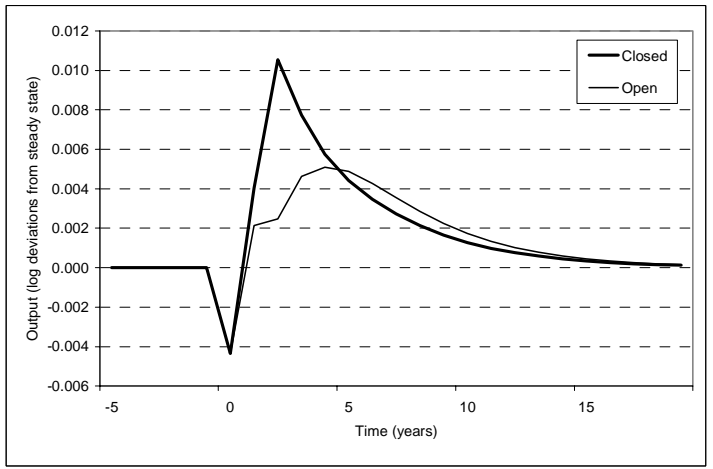

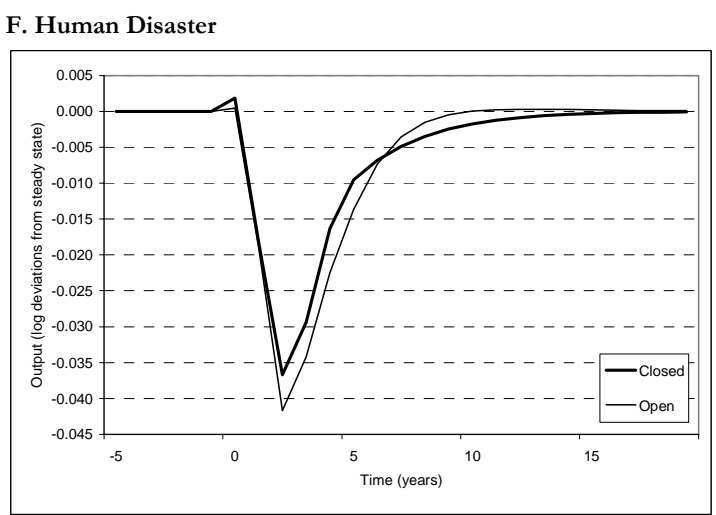




\section{Figure 7: External shocks in Highly Indebted Countries (HIPCs)}

The different panels of the figure compare the impulse-response functions of log real per capita GDP to different external shocks in Highly Indebted Poor Countries (HIPCs) and the rest of low income countries. Panel A shows the IRF to a one standard deviation shock to the log real GDP per capita of high income OECD countries. Panel B shows the IRF of log GDP to a one standard deviation shock to the process followed by the log Deaton Miller commodity based terms of trade index (DM index). Panel C presents the IRF to a one standard deviation to the log six month nominal LIBOR rate. Panels D to F show the IRF to a Geological, Climatic, and Humanitarian disasters respectively. Panel G presents the IRF to a one standard deviation shock to real per-capita aid flows. The time horizon is in years.

\section{A. Shock to rich countries GDP}

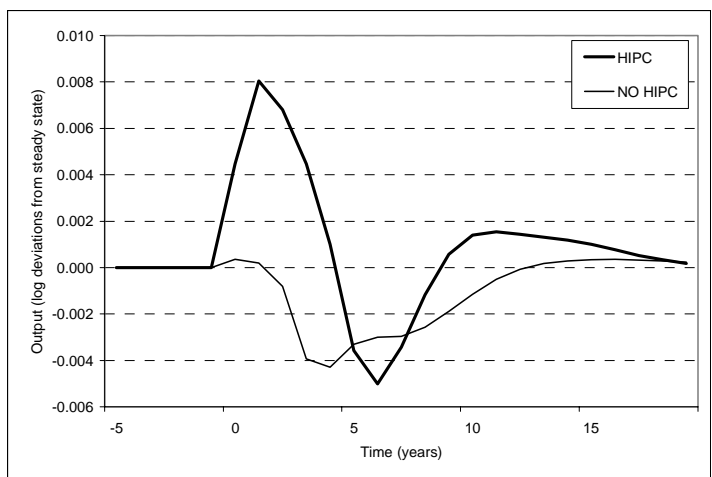

C. Shock to international interest rates

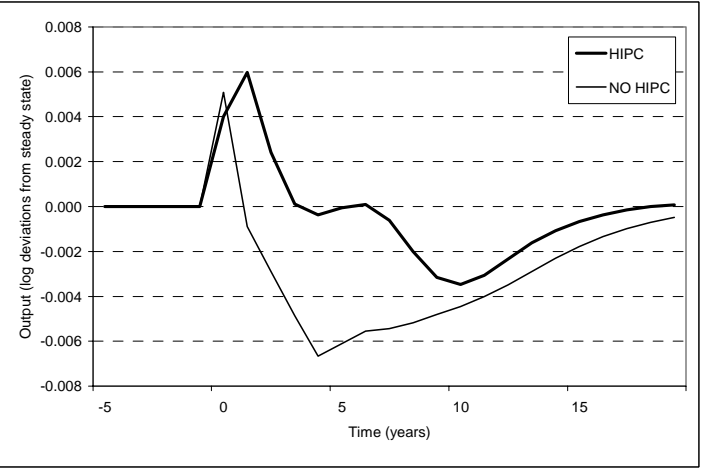

B. Shock to DM commodity prices index

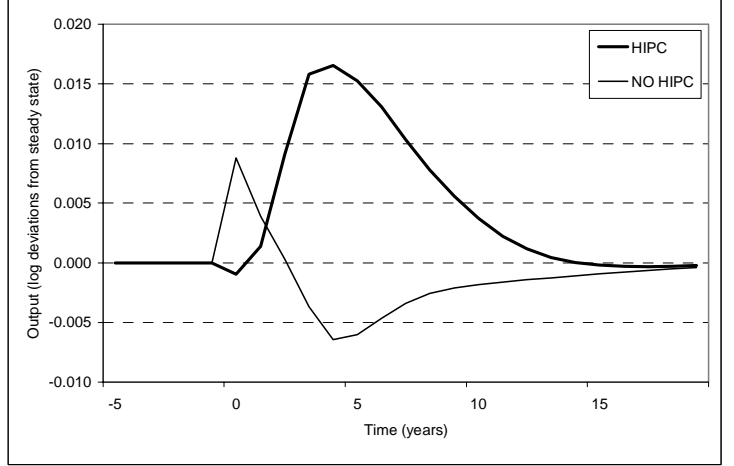

D. Geological Disaster

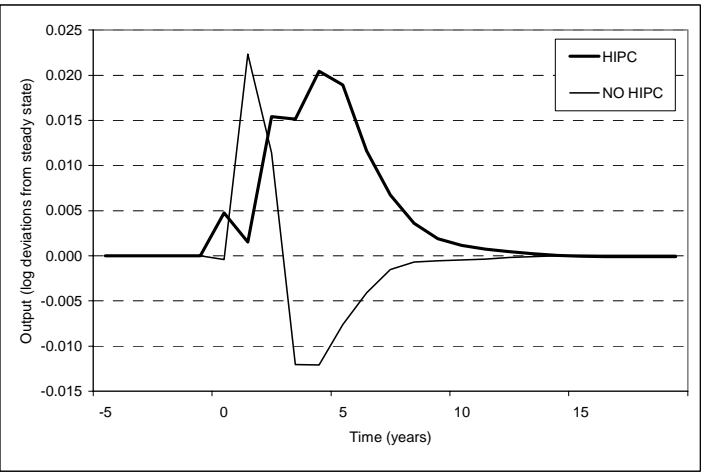

Continues next page 
Figure 7 continued

E. Climatic Disaster

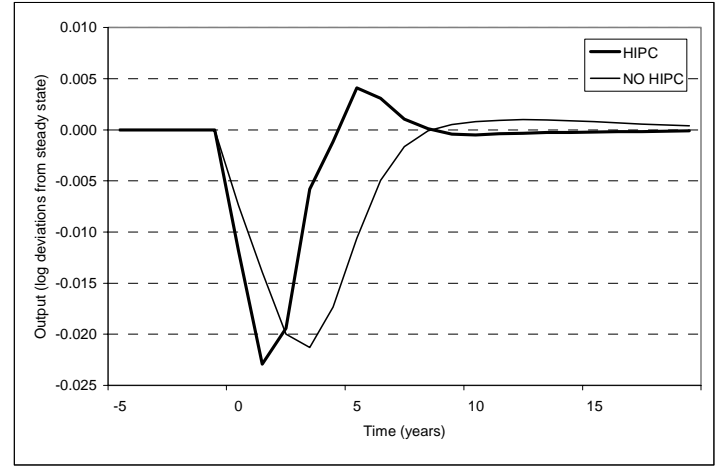

G. Shock to real per capita aid flows

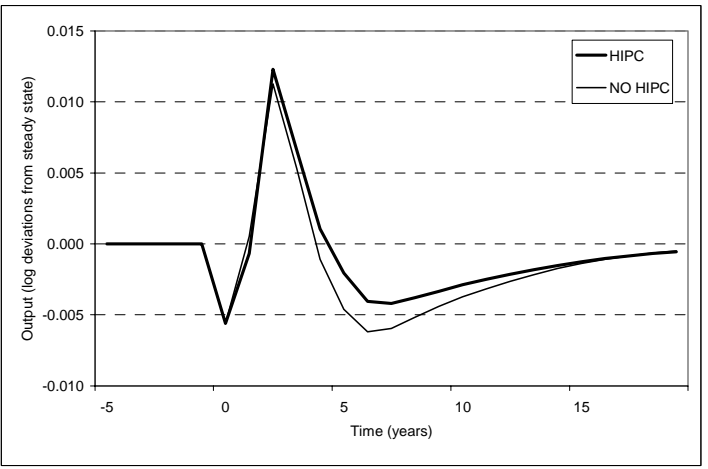

F. Human Disaster

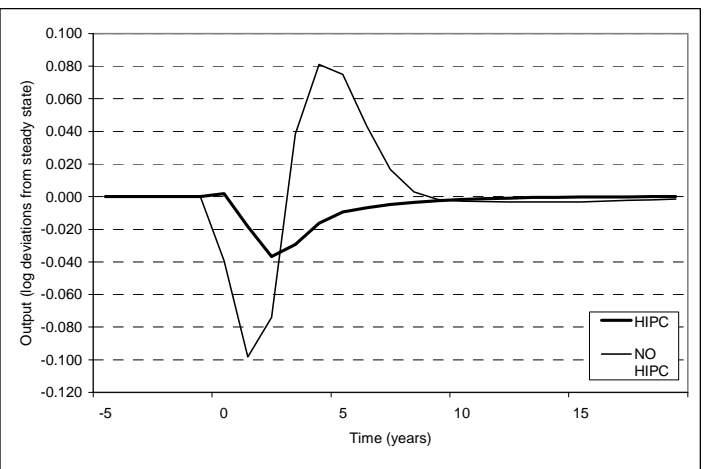




\section{Figure 8: External shocks and Institutions}

The different panels of the figure compare the impulse-response functions of log real per capita GDP to different external shocks in low income countries with indicators of law and order above and below the group median. Panel A shows the IRF to a one standard deviation shock to the log real GDP per capita of high income OECD countries. Panel B shows the IRF of log GDP to a one standard deviation shock to the process followed by the log Deaton Miller commodity based terms of trade index (DM index). Panel C presents the IRF to a one standard deviation to the log six month nominal LIBOR rate. Panels D to F show the IRF to a Geological, Climatic, and Humanitarian disasters respectively. Panel G presents the IRF to a one standard deviation shock to real per-capita aid flows. The time horizon is in years.

\section{A. Shock to rich countries GDP}

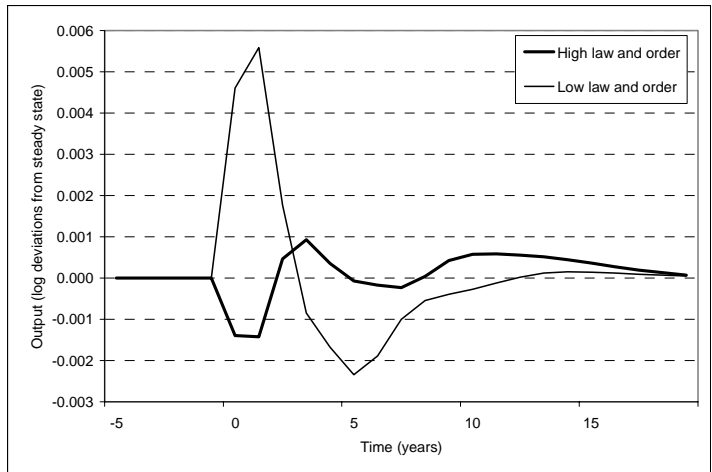

C. Shock to international interest rates

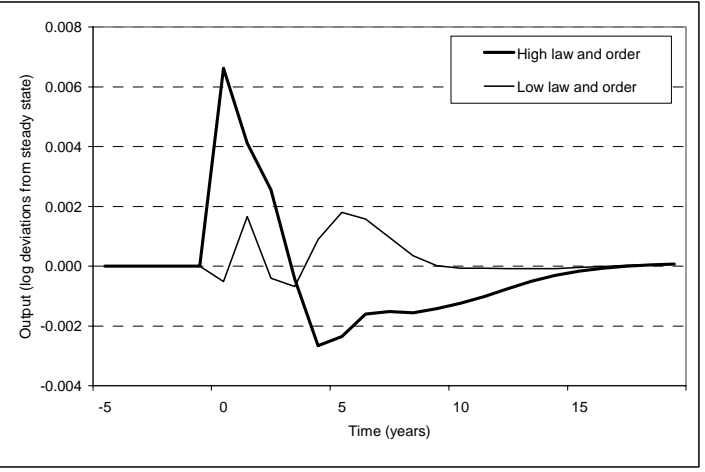

B. Shock to DM commodity prices index

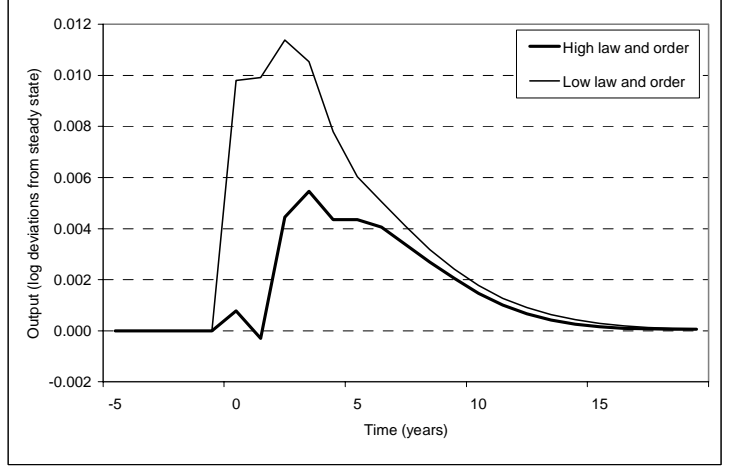

D. Geological Disaster

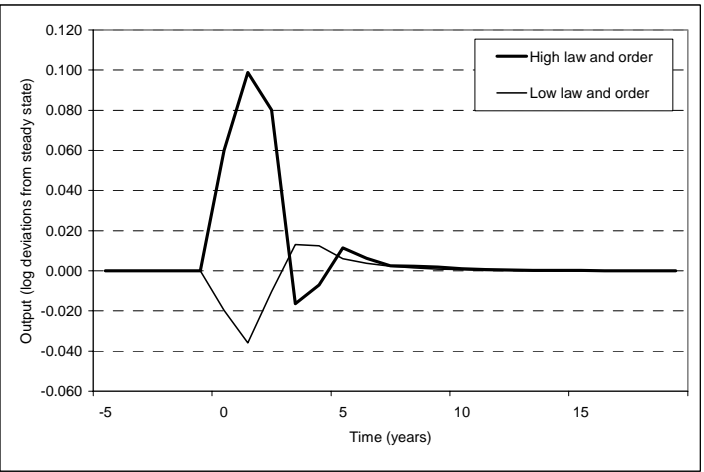

Continues next page 
Figure 8 continued

E. Climatic Disaster

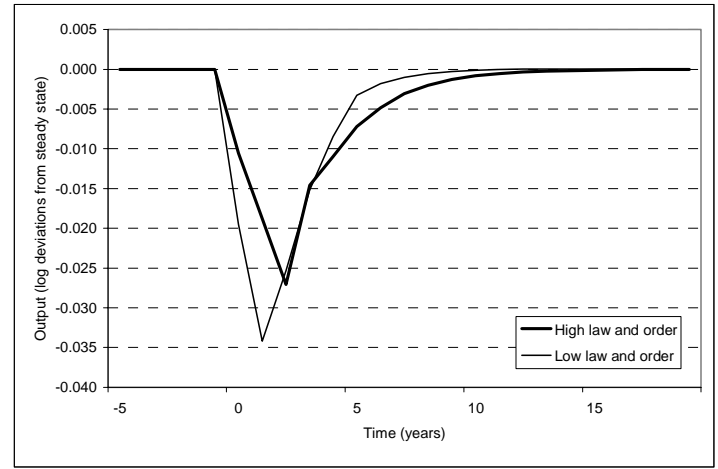

G. Shock to real per capita aid flows

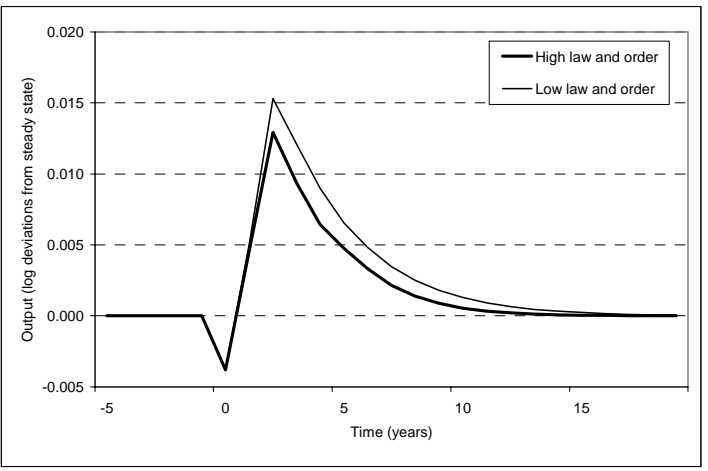

F. Human Disaster

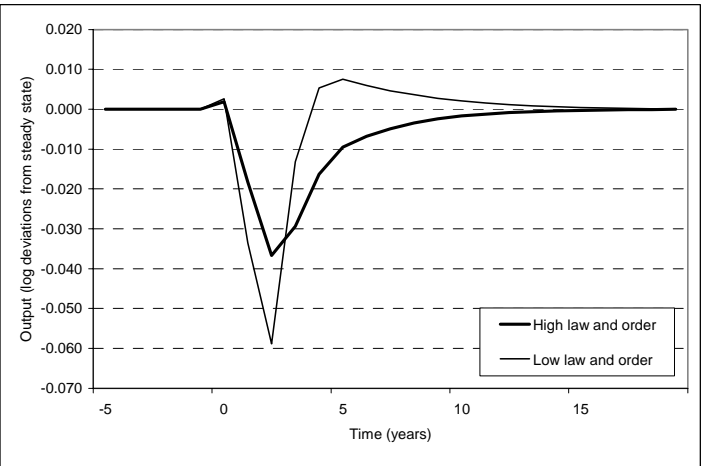

